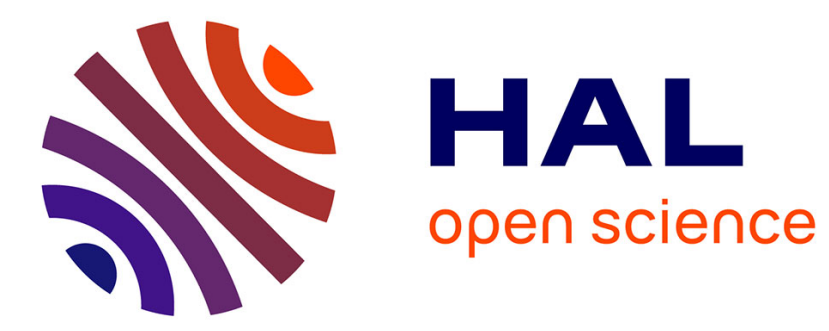

\title{
Targeting lipid metabolism in liver cancer
}

Malak Alannan, Hussein Fayyad-Kazan, Véronique Trézéguet, Aksam Merched

\section{To cite this version:}

Malak Alannan, Hussein Fayyad-Kazan, Véronique Trézéguet, Aksam Merched. Targeting lipid metabolism in liver cancer. Biochemistry, 2020, 59 (41), pp.3951-3964. 10.1021/acs.biochem.0c00477 . hal-03373099

\section{HAL Id: hal-03373099 \\ https://hal.science/hal-03373099}

Submitted on 11 Oct 2021

HAL is a multi-disciplinary open access archive for the deposit and dissemination of scientific research documents, whether they are published or not. The documents may come from teaching and research institutions in France or abroad, or from public or private research centers.
L'archive ouverte pluridisciplinaire HAL, est destinée au dépôt et à la diffusion de documents scientifiques de niveau recherche, publiés ou non, émanant des établissements d'enseignement et de recherche français ou étrangers, des laboratoires publics ou privés. 


\title{
Targeting lipid metabolism in liver cancer
}

\author{
Malak Alannan ${ }^{1,2}$, Véronique Trézéguet ${ }^{1 *}$, Aksam Merched $^{1,3,4^{*}}$
}

${ }^{1}$ Université de Bordeaux, INSERM U1035, miRCaDe team, Biothérapie des Maladies

Génétiques, Inflammatoires et du Cancer, Bordeaux 33076, France

${ }^{2}$ Faculty of Sciences I, Rafic Hariri Campus - Hadath, Lebanon

${ }^{3}$ Department of Molecular and Cellular Biology, Baylor College of Medicine, Houston, TX, USA

${ }^{4}$ Present address: Université de Bordeaux, INSERM U1035, miRCaDe team, Biothérapie des Maladies Génétiques, Inflammatoires et du Cancer, Bordeaux 33076, France

*Correspondence to: aksam.merched@u-bordeaux.fr, veronique.trezeguet-busquet@ubordeaux.fr

Keywords: Lipid metabolism, cancer, liver diseases, fatty acids, Acetyl-CoA, inflammation 


\section{Abstract}

Cancer cells are highly dependent on different metabolic pathways to sustain their survival, growth and proliferation. Lipid metabolism supplies not only energetic needs of the cells but also provides the raw material for cellular growth and the signaling molecules for many oncogenic pathways.

Mainly processed in the liver, lipids play an essential role in the physiology of this organ and string the pathological progression of many diseases such as metabolic syndrome and hepatocellular carcinoma (HCC). The progression of HCC is associated with inflammation and complex metabolic reprogramming, and its prognosis remains poor because of the lack of effective therapies despite many years of dedicated research.

Defects in hepatic lipid metabolism induce abnormal gene expression and rewires many cellular pathways involved in oncogenesis and metastasis, implying that interfering with lipid metabolism within the tumour and surrounding microenvironment may be a novel therapeutic approach for treating liver cancer patients. Therefore, this review focuses on the latest advances in drugs targeting the lipid metabolism and leading to promising outcome in preclinical studies and some ongoing clinical trials. 


\section{ABBREVIATIONS}

24,25-EC, 24(S),25-epoxycholesterol ; ACC, acetyl-CoA carboxylase ; ACLY, ATP-citrate lyase; ACSL1, acyl-CoA synthetase long chain family member 1; ACSS1/2, acetyl CoA synthetase short chain family member 1/2; AKT 1/2/3, Protein kinase B 1/2/3; AT-LX, aspirin Triggered-lipoxins; Bcl-2, B-Cell Leukemia/Lymphoma 2; Bcl-xL, B-cell lymphoma-extra large; C16:0, palmitic acid ; ChoEs, cholesterol esters; COX2, cyclooxygenase-2; CPT1, carnitine palmitoyltransferase 1 ; CPT1A, B or C, carnitine palmitoyltransferase 1 isoform A, $\mathrm{B}$ or $\mathrm{C}$; CREB, cAMP response element-binding protein; DIPG, diffuse intrinsic pontine glioma; ERK, extracellular signal-regulated kinases; FA, fatty acid; FAO, fatty acid betaoxidation; FAS, Tumour necrosis factor receptor superfamily member 6; FASN, fatty acid synthase; FOXP3, forkhead box P3; GPC3, glypican 3; HCC, hepatocellular carcinoma; HMGCoA, $\beta$-Hydroxy $\beta$-methylglutaryl-Coenzyme A; HMGCR, HMG-CoA reductase; Il-10, interleukine 10; LOA, loss of attachment ; LPC, lysophosphatidylcholines; LSS, lanosterol synthase; LXR, liver X receptor; M1 or M2, M1 or M2 type macrophage; Mcl-1, Induced myeloid leukemia cell differentiation protein 1; mPGES1, microsomal PGE2 synthase 1; mTOR, mammalian target of rapamycin ; mTORC1 or 2, mTOR complex 1 or 2 ; NAFLD, non-alcoholic fatty liver disease; NASH, non-alcoholic steatohepatitis; NFkB, nuclear factor кB; OXPHOS, mitochondrial oxidative phosphorylation; PC, phosphatidylcholines ; PD-L1, programmed death-ligand 1; PE, phosphatidylethanolamine ; PGE2, prostaglandin E2 ; PI, phosphatidylinositol ; PI3K, phosphatidylinositol 3-kinase; PML, promyelocytic leukemia protein ; PPAR $\beta / \delta$, peroxisome proliferator-activated receptor $\beta / \delta$; PUFA, polyunsaturated fatty acid; REDD1, regulated in development and DNA damage responses; ROS, reactive oxygen species; SCD, stearoyl-CoA desaturase; SM, sphingomyelin ; SPM, specialized proresolving mediators; SREBP, sterol regulatory element-binding protein; TAM, tumour associated macrophages; TF, transcription factor; TG, triglyceride or triacylglycerol; TGF- $\beta$, 
transforming growth factor beta; Treg, regulatory immunosuppressive T cell; TSC1, tuberous sclerosis complex 1 ; VEGF, vascular endothelial growth factor. 
Introduction

Glucose and glutamine metabolism, tricarboxylic acid cycling, oxidative phosphorylation, pentose phosphate pathway and amino acid and lipid synthesis are all essential for the production of cellular components to cope with a faster growth rate. Indeed, the growth and expansion of tumours require a massive and complex system that coordinates to provide the necessary nutrients. They also depend on the microenvironment including the extracellular matrix, the nearby cells, of which immune cells, and growth factors like cytokines. Cancer cells require a larger supply of energy than normal cells to fulfill their needs. Therefore, their metabolism is expected to be modulated to meet their continuous demand for energy, which is provided in the form of ATP produced by the conversion of various metabolites such as glucose, lactate, pyruvate, glutamine or fatty acids. Cancer cells usually originate from genetic mutations or epigenetic alterations, leading to reprogramming of their signaling and metabolic pathways (1). In the recent past, there has been a growing interest in reprogramming many metabolic pathways such as glucose, glutamine or lipid metabolism. This last point will be the focus of this review.

Adult liver cancer is ranked second fatal cancers worldwide (2). It develops on a diseased liver and its incidence rate has increased steadily over the past decade due to the rise of viral hepatitis $\mathrm{B}$ or $\mathrm{C}$ infections, or environmental toxins as well as to the increase incidence of chronic liver diseases, such as non-alcoholic steatohepatitis (NASH) and non-alcoholic fatty liver diseases (NAFLD). It should be noted that NAFLD develops in patients with metabolic syndromes such as type 2 diabetes mellitus, obesity, hypertension and hyperlipidemia $(3,4,5)$. Most of the primary liver cancers in adults are hepatocellular carcinomas (HCC), which account for $90 \%$ of all cases.

Liver cancers are characterized by modulation of the "Warburg Shift" and up-regulation of lipid catabolism (6). During the Warburg shift, even in the presence of adequate amounts of 
oxygen, cancer cells tend to generate energy from aerobic glycolysis instead of mitochondrial oxidative phosphorylation (OXPHOS), resulting in increased uptake of glucose, generation of ATP and production of lactate (7). In this way, faster energy is supplied along with a carbon source, which is necessary for the anabolic synthesis of essential precursors. Moreover, by turning down their OXPHOS, cancer cells can reduce the amount of reactive oxygen species (ROS) which are highly reactive metabolites known to cause significant damage to cell structures.

Next in this review, we will dissect the main anabolic and catabolic pathways of the lipid metabolism e.g. lipogenesis and fatty acid oxidation with more emphasis on the acetyl-CoA at the forefront, which is a metabolic node located at the center of many metabolic pathways (Figure 1). In this context, we show how interfering with the production and fates of this key metabolite modulates oncogenesis. This will set the stage for the assessment of drugs targeting specific and critical steps of the complex lipid metabolic network in liver cancer. 


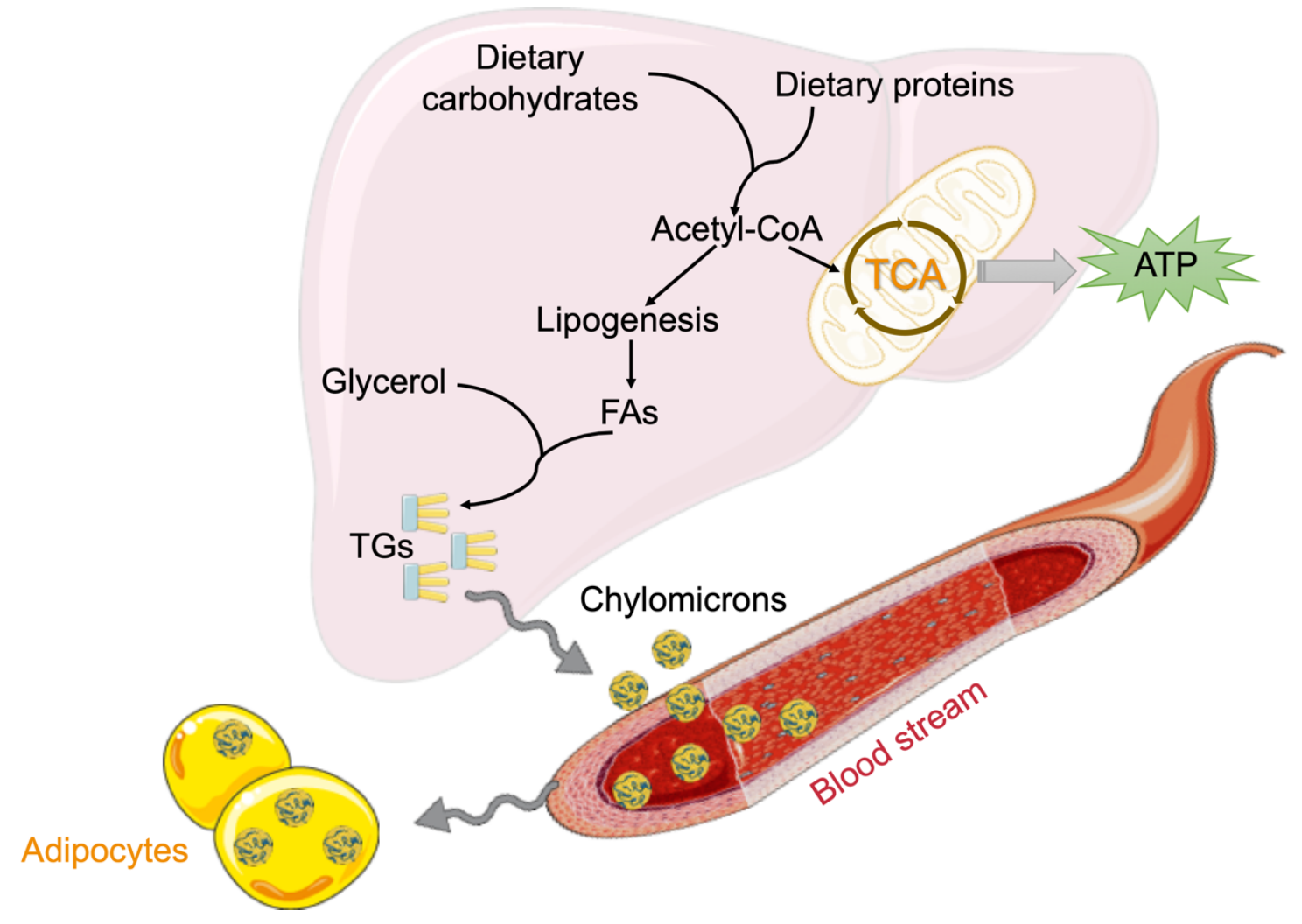

Figure 1. Overview of lipid metabolism. Carbohydrates and proteins originated from diet will be metabolized by the liver to produce acetyl-CoA, a main key player in the metabolic reactions. Acetyl-CoA can enter the TCA cycle in the mitochondria to produce energy. It can also be used to produces FAs by a process termed lipogenesis. These FAs together with the glycerol will give rise to TGs that will be incorporated together with cholesterol, PLs and proteins into structures called chylomicrons. The chylomicrons will be transferred through blood stream to adipose tissues which are the main energy stores. During long fasting periods, these lipid particles will serve as great source of energy through FAO and autophagy.

\section{Acetyl-CoA, lipid metabolism and oncogenesis}

Acetyl-CoA is a central metabolite at the crossroads of many metabolic pathways and transformations (Figures 1 and 2). Not only it is utilized in the synthesis of essential macromolecules needed by the cells, but also is used in multiple catabolic and anabolic reactions including synthesis of FAs, steroids and non-sterol compounds (8). Indeed, Acetyl- 
CoA derives from multiple metabolic reactions occurring in the cell, such as glucose, fatty acid and amino acid catabolism. The importance of this molecule resides in its different implications in many cellular processes including: energy production by tricarboxylic acid (TCA) cycle inside the mitochondria, serving as a building block molecule for the synthesis of macromolecules like FAs and sterols in the cytosol, as well as being an important nucleocytosolic molecule for acetylation of histones and thus activation of gene expression (9).

It is important to distinguish between the cytosolic and mitochondrial acetyl-CoA, as either forms cannot freely transfer between the cell compartments. Mitochondrial acetyl-CoA (mAcCoA) can be derived from pyruvate, FAO as well as acetate, whilst cytosolic acetyl-CoA (cAcCoA) can be derived from acetate, citrate and ketone bodies $(9,10)$. All of these are catalyzed by different enzymes such as acetyl-CoA synthetase (ACSS) and ATP citrate lyase (ACL/ACLY) (11) (Figure 2).

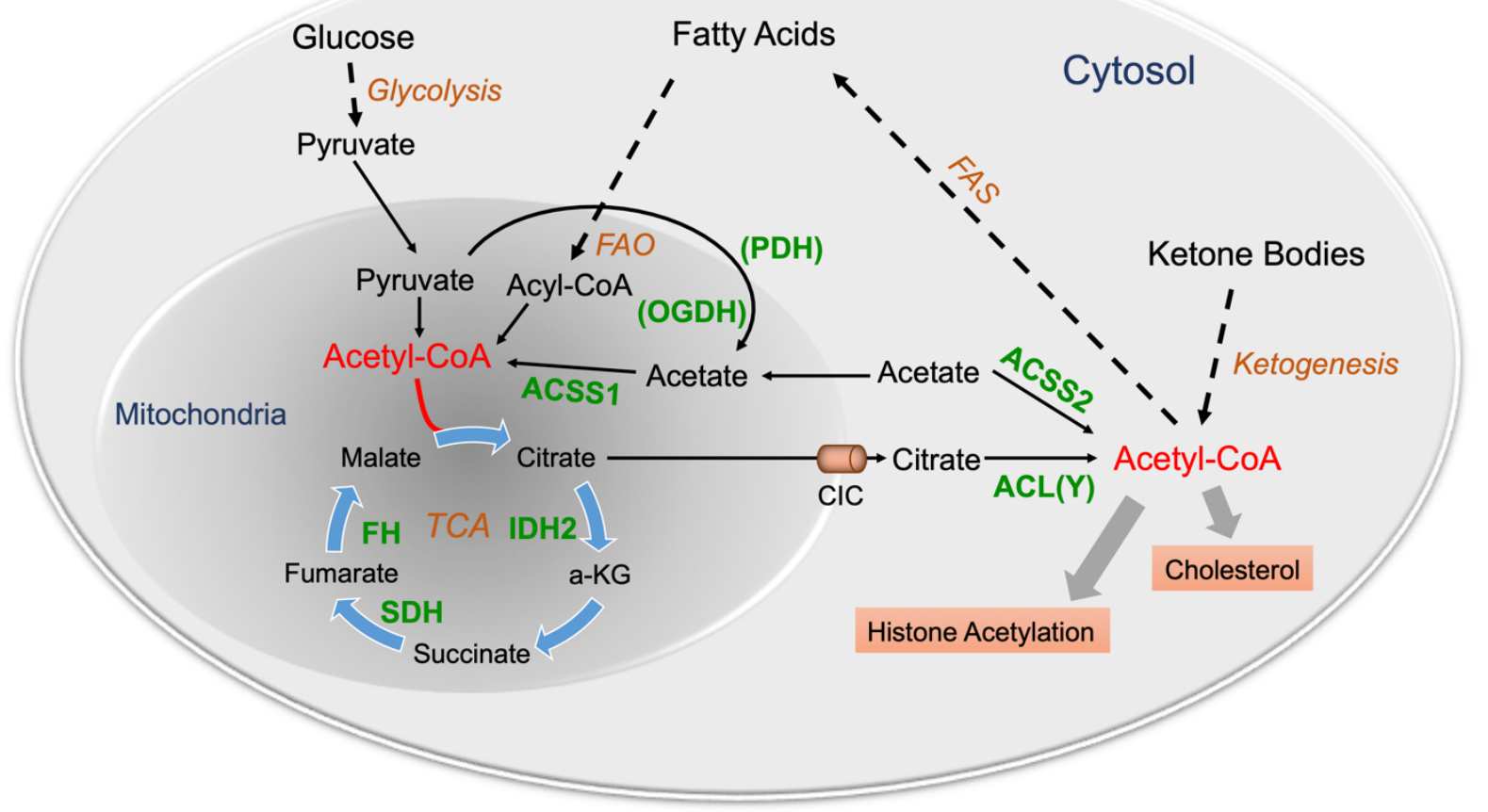

Figure 1. Metabolic pathways to generate and utilize acetyl-CoA. Acetyl-CoA can be produced by many metabolic pathways, of which we can find the mitochondrial and cytosolic acetyl- 
CoA. The enzymes involved in its production are highlighted in green. The transport of acetate and citrate from and to the mitochondria is made possible by their respective carriers. TCA: tricarboxylic acid cycle; FAO: fatty acid oxidation; FAS; fatty acid synthesis; $\alpha-\mathrm{KG}$ : $\alpha$ ketoglutarate; IDH2: isocitrate dehydrogenase 2; $\mathrm{SDH}$ : succinate dehydrogenase; FH: fumarate hydratase; ACSS1: mitochondrial Acetyl-CoA synthetase short chain family member 1; ACSS2: cytosolic Acetyl-CoA synthetase short chain family member 1; ACL(Y): ATP-citrate lyase; PDH: Pyruvate dehydrogenase; OGDH: oxaloglutarate dehydrogenase (parentheses mean neomorphic function of the enzymes (15)).

Under nutrient deprivation conditions, the cells need to shift their metabolism from growth towards survival in order to ensure viability. In this condition, cells need to direct acetyl-CoA into the mitochondria in order to produce energy and hence, the nucleocytosolic acetyl-CoA decreases. It is noteworthy to mention that, in the liver, mAc-CoA can be used to produce ketone bodies, such as acetoacetate and $\beta$-hydroxybutyrate, which serve as fuel sources for the heart and brain in starvation conditions (12).

The critical uses of acetyl-CoA and its implication in the survival and growth of cancer cells in both nutrient abundant and deprived conditions led many researches to focus on modulating the production and fates of this molecule (Table 1). Some of these approaches were done by blocking the transport of citrate from mitochondria to the cytosol through citrate carriers (CIC) by the action of benzene tricarboxylate analogue (BTA). BTA has shown some anti-cancer effects in various tumours and in xenograft mice model (13), making it possible to be used alone or in combination with other metabolic modulators, as anti-cancer agents. Another way to block acetyl-CoA production is by using an inhibitor of the enzymes ACSS (ACSS 1 to 3 ) which catalyze the production of acetyl-CoA from acetate. 
A recent study reported high expression of ACSS2 in cisplatin-resistant bladder cancer patient tissues and showed that the use of an ACSS2 inhibitor leads to the abrogation of resistance in cisplatin-resistant bladder cancer cells (14).

Table 1. List of some potential anti-cancer drugs targeting lipid metabolism

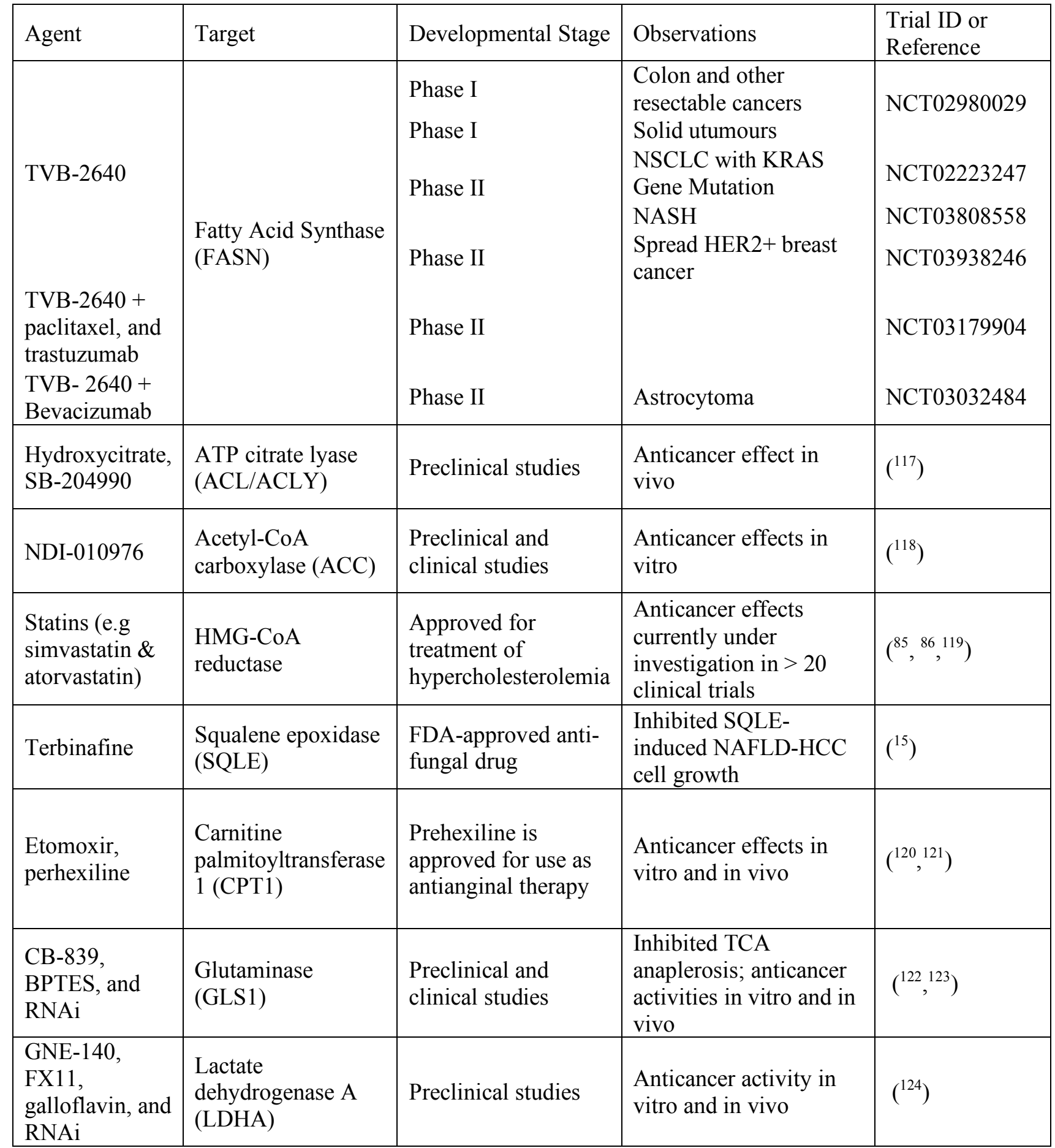




\begin{tabular}{|c|c|c|c|c|}
\hline Metformin & $\begin{array}{l}\text { Mitochondrial } \\
\text { complex I and } \\
\text { ACC }\end{array}$ & $\begin{array}{l}\text { Approved for } \\
\text { treating type } 2 \\
\text { diabetes }\end{array}$ & $\begin{array}{l}\text { Phase II clinical trials in } \\
\text { patients with breast } \\
\text { cancer }\end{array}$ & NCT01266486 \\
\hline $\begin{array}{l}\text { Acetylsalicylic } \\
\text { Acid (Aspirin) } \\
\text { Combined with } \\
\text { Sorafenib }\end{array}$ & Analgesic & & $\begin{array}{l}\text { A Prospective } \\
\text { Randomized Control } \\
\text { Trial to Prevent the } \\
\text { Recurrence in High-risk } \\
\text { Patients With HCC }\end{array}$ & NCT02748304 \\
\hline
\end{tabular}

The lipid anabolic reactions termed 'De novo lipogenesis' and 'Mevalonate pathway' take place in the cell cytosol (Figure 3). Higher lipogenesis is a characteristic feature of cancer cells requiring the rate-limiting enzyme acetyl-CoA carboxylase (ACC) which catalyzes the irreversible carboxylation of acetyl-CoA to malonyl-CoA (16). The reverse decarboxylation reaction is catalyzed by yet another enzyme named malonyl-CoA decarboxylase (MCD) which in turn inhibits lipogenesis and stimulates $\beta$-oxidation (17). Then acetyl-CoA combines with malonyl-CoA by fatty acid synthase (FASN) to produce fatty acids, which can be metabolized to produce TGs or phospholipids. TGs can be stored in lipid droplets as a reserve energy source, while phospholipids are necessary for membrane synthesis and serve as signaling molecules (Figure 3). By using some specific inhibitors and other drugs inhibiting these enzymes and pathways, many studies have assessed their potential anti-tumoural involvement. 


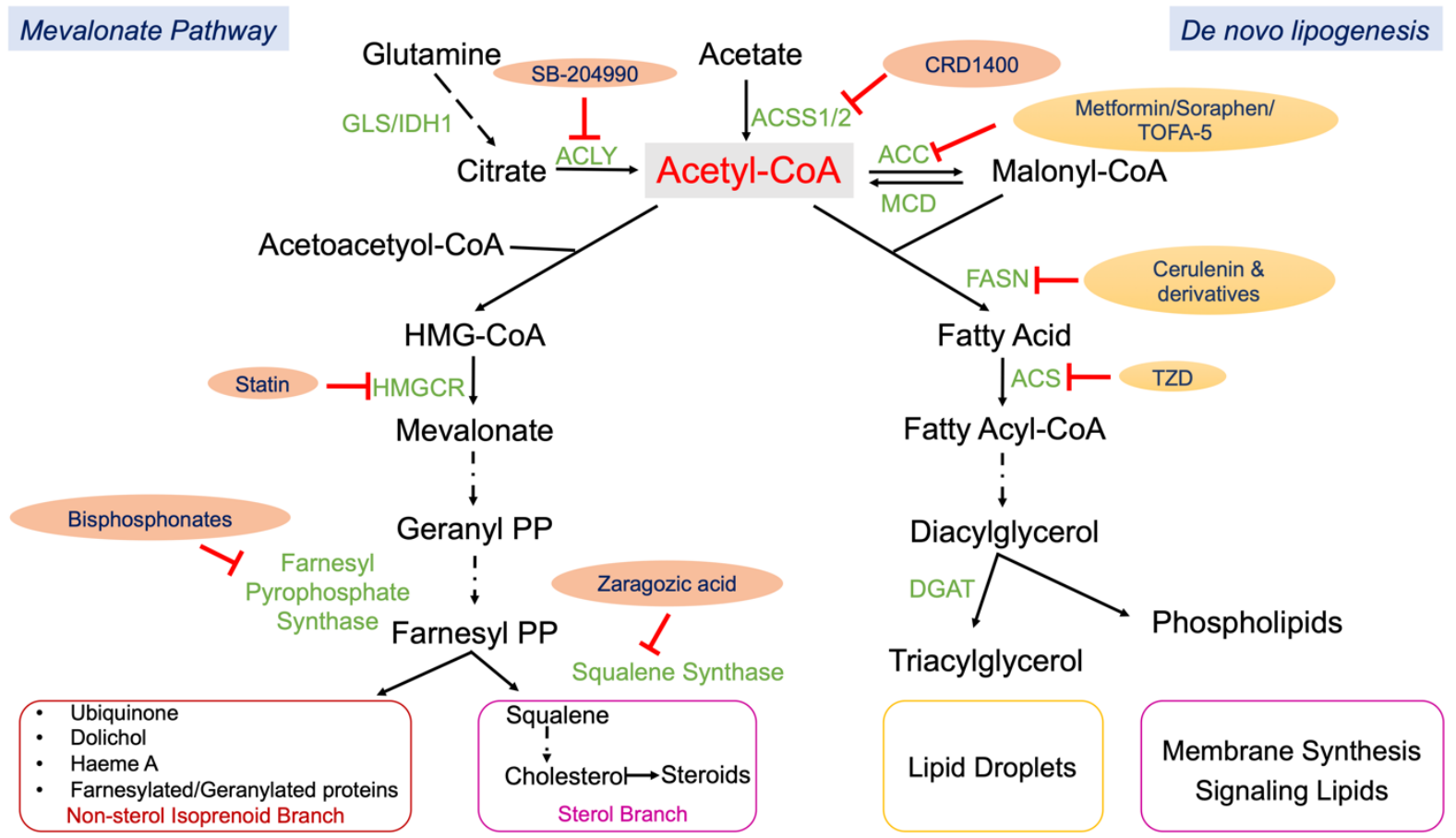

Figure 3. Drug targeting of lipid metabolic pathways. Acetyl-CoA can be incorporated into two anabolic pathways: mevalonate pathway (left side) to produce sterols and non-sterol compounds or fatty acid synthesis (right side) leading to the production of TGs and PLs. Enzymes catalyzing the reactions are highlighted in green, and their respective inhibitors are shown in oval shapes.

For instance, metformin which is a known drug widely prescribed to treat patients suffering from type 2 diabetes mellitus was used in a mouse model with chemically induced liver tumours (18). In this study, metformin was shown to protect mice from the induction of liver tumours by decreasing the expression of ACC, FASN and ACLY. In addition, this drug was shown to have antineoplastic effects in breast cancer cells which are associated with mammalian target of rapamycin (mTOR) and S6 kinase activation (19). Moreover, metformin was reported to be a very good chemopreventive agent in lung cancer in mice where it indirectly inhibited mTOR activation 20 . 
Another family of drugs, soraphens (Soraphen A) which are antifungal myxobacterial metabolites (21) were discovered to have anti-cancer role by inhibiting ACC enzyme (22). This inhibition changes the phospholipid composition of cellular membranes and interfere with their dynamics (23). Moreover, it was shown that Soraphen A impedes the recycling process, dimerization and localization of growth factor receptors which are necessary for the protumourigenic signaling cascade of cancer cells (24).

TOFA (5-tetradecyloxy-2-furoic acid) is yet another allosteric inhibitor of ACC that proved to be cytotoxic and induces apoptosis in the lung cancer cell line NCI-460, colon cancer cell lines HCT-8 and HCT-15, and prostate cancer cell line $\operatorname{LNCaP}(25,26)$. Moreover, it suppressed the ovarian cancer cell proliferation, induced cell cycle arrest and apoptosis (27) in vitro and in vivo.

The second anabolic pathway of lipid metabolism using acetyl-CoA is the mevalonate pathway which leads to the production of sterol and non-sterol molecules, such as cholesterol and ubiquinone, respectively. This pathway is catalyzed by the rate-limiting enzyme, $\beta$ Hydroxy $\beta$-methylglutaryl-Coenzyme A reductase (HMGCR) which is the direct target of statins (further discussed below). Along this pathway, other enzymes catalyzing the reaction can be targeted, such as farnesyl pyrophosphate synthase that can be inhibited by bisphosphonates (BPs). BPs are widely used as effective antiresorptive therapies in osteoporosis. The nitrogen-containing BPs prevents the prenylation of small GTPases (e.g. Ras) and thus causes apoptosis in J774 macrophages and osteoclasts in vivo and in vitro $(28,29)$. Zaragozic acid, on the other hand, inhibits squalene synthase, blocks the synthesis of cholesterol downstream of mevalonate formation and inhibits the growth of Rauscher virustransformed lymphoma and Lewis lung carcinoma in vivo (30). Moreover, the molecule was capable of potentiating the antitumour effects of active and adoptive immunotherapy by 
prolonging the overall survival of tumour-bearing mice highlighting the potential anti-tumour role of this compound.

\section{Lipogenesis in liver cancer cells}

In tumour cells, not only the Warburg shift, but also the lipid catabolism is increased due to the importance and necessity of lipid molecules. Fatty acids (FA) are considered to be a great source of energy and can be used by cells for growth and proliferation. They can be obtained from extracellular media, hydrolysis of triglycerides (TG) or via de novo synthesis (also known as lipogenesis) (6). Increased lipogenesis is an emerging metabolic hallmark of (2). Together with lipolysis, these processes promote tumour growth, proliferation and survival. The central question is then why cancer cells depend on lipid metabolism.

The primary organ of lipid metabolism is the liver, of which it is the main function, through the maintenance of lipid homeostasis and energy balance. FAs are mainly synthesized in the liver and mostly from dietary carbohydrates, which are transformed into acetyl-CoA, leading to lipogenesis. After a series of elongation and desaturation processes, three fatty acids combine with one glycerol molecule to produce TG, which is then packaged into lipoprotein particles with cholesterol, phospholipids and proteins in order to be released into the blood stream. They are stored in the adipocytes in the form of lipid droplets or transferred to the muscles to supply energy metabolism. During long periods of fasting, the cells are capable of producing energy from these lipid stores through different processes such as fatty acid betaoxidation (FAO) or even autophagy (31). Therefore, normal liver physiology depends largely on the balance of the lipid metabolism, any disruption of which can induce inflammation and fibrogenesis as well as fatty liver diseases and HCC.

Metabolic profiles of cancer cells have been characterized by a growing number of studies aiming at better understanding cancer cell behavior and possibly discovering biomarkers 
related to hepatic oncogenesis and proposing more adapted therapeutic approaches (32). The development of carcinoma in the liver is taking place through intermediate phases such as NAFLD/NASH or cirrhosis and depends on various alterations of metabolic pathways. Thus, the deregulation of bile acids and phospholipids is observed in the early stages of liver diseases, followed in the advanced stages by an increase in the Warburg shift and lipid catabolism (6). Metabolomics studies conducted on HCC have shown that the enhancement of the Warburg effect is attributable to an increase in glycolysis along with an increase in beta-oxidation, making it common metabolic hallmarks of the tumour $(33,34,35,36)$. This metabolic reprogramming observed during progression to $\mathrm{HCC}$ is considered a common feature of tumours.

Serum lipid profiling by ultra-fast LC/IT-TOF MS has been effective in highlighting differences in the lipidome of healthy patients and with liver diseases (37). Indeed, Chen et al. (37) were able to identify 96 serum lipids, 75 of which were differently regulated: eight sphingomyelin (SM), ten polyunsaturated phosphatidylcholines $\quad(\mathrm{PC}), \quad$ six lysophosphatidylcholines (LPC), ten TG and two cholesterol esters (ChoEs) were downregulated for patients with cirrhosis and HCC, compared to healthy ones and with hepatitis. These analyses have revealed lipidomic differences according to the stage of HBV-induced liver disease. It is interesting to note that a saturated PC, PC (32:0), was up-regulated for all diseased patients, but more extensively for those with cirrhosis and HCC. This could be related to its protective role against oxidative stress for cancer cells (23). Li et al. (38) performed lipid analyses of HCC liver along with the corresponding para-carcinoma tissues, also reported deregulation of 53 lipids. The level of TG deregulation was dependent on the number of double-bonds. Down-regulation was observed for TG with more than 2, while those with 2 or less double-bonds were more abundant. Furthermore, the authors found a positive correlation between the severity of the disease, higher concentrations of saturated TGs and lower 
concentrations of polyunsaturated TGs in HCC tissues. PC, phosphatidylethanolamine (PE) and phosphatidylinositol (PI) containing 0,1 and 3 double bonds were up-regulated and those presenting 2, 4 and 6 double bonds were down-regulated. Lin et al. (39) analyzed the lipid content of HCC cells with various metastatic abilities and found up to $25 \%$ reduction of the levels of palmitic acyl (C16:0)-containing phosphoglycerolipids which was associated with increasing metastatic abilities of these cells. Therefore, they have investigated the antitumour activity of palmitic acid (C16:0). Treatment of highly metastatic HCC cells by palmitic acid showed inhibition of cell proliferation, migration and invasion, decrease in cell membrane fluidity, inhibition of glucose uptake and thus affected malignant behaviors of cancer cells. Moreover, treatment of nude mice bearing cell carcinoma xenografts by palmitic acid led to the suppression of both subcutaneous tumour growth and metastatic nodule formation (15).

In summary, the differential abundance of certain lipids in HCC can potentially be used to identify new biomarkers of HCC, but could also open the way to new therapeutic approaches in a lipid metabolism context.

\section{Fatty Acid Oxidation in liver cancer}

Most of the cancer research focuses on the effect of glycolysis, glutaminolysis and FA synthesis on cancer cell function. Less attention has been paid to the importance of lipid catabolism in HCC and other cancer types (40). Lipid catabolism shares some common oncogenic functions with glycolysis as an important energy provider supporting cell survival and growth, and providing the intermediate metabolites for biosynthesis processes in the fast growing tumour (32). The two main energy sources in the human body, glycogen and TG, are both synthesized in the liver. The very first to be consumed during short-time fasting is glycogen. Once depleted, cells are capable of switching to TG, which can provide six times as much ATP as glycogen, making it the preferred energy storage form (32). The catabolism of 
fatty acids occurs through FAO -also known as B-oxidation- mostly in energy-demanding tissues such as the heart and skeletal muscles as well as in the liver. Basically, what happens during FAO is, FAs are transported from the blood stream into the cells where they will be transformed into fatty-acyl CoA by the action of Fatty Acyl-CoA Synthetase (FACS). Longchain fatty-acyl CoA will enter the mitochondria only after being converted to acyl carnitine by the action of carnitine palmitoyltransferase 1 (CPT1). Once inside the mitochondria, it will be converted back to fatty acyl-CoA by CPT2 which will then enter in a series of oxidation reactions to yield acetyl-CoA and most importantly energy in the form of ATP (41).

Highly proliferative tumour cells and specially poorly vascularized cells in solid tumours experience high metabolic stress related to the lack of nutrients and oxygen and may undergo apoptosis (32). However, almost all cancer cells are resistant to the programmed cell death through different metabolic and non-metabolic processes. For instance, resistant HCC cells can counteract that effect by increasing FAO, regardless of the availability of glucose or glycogen. Indeed, unlike sensitive cells, resistant cells can survive under starvation by activating lipid catabolism (42), thus confirming the essential role of FAO in cell survival and tumour progression. This process is also involved during loss of attachment (LOA) when tumour cells lose contact with the nearby extracellular matrix. In anchorage-dependent cells, LOA causes anoikis, an apoptotic process resulting from insufficient cell-matrix attachment. However, metastatic tumour cells may escape from anoikis and invade different locations. Indeed, antioxidants and oncogenes, such as promyelocytic leukemia protein (PML) and carnitine palmitoyltransferase 1 (CPT1) isoform $\mathrm{C}(\mathrm{CPT} 1 \mathrm{C})$ upregulate FAO to promote cell survival during LOA (43, 44, 45). Pharmacological inhibitors of FAO, initially developed to treat diabetes or cardiopathies, can induce cancer cell death in vitro as well as in mice models. This was the case of etomoxir, an irreversible inhibitor of CPT1A and B and ST1326, a new reversible inhibitor highly selective for CPT1A (the liver isoform). Etomoxir was capable of 
re-sensitizing leukemia cells to chemotherapy-induced cell death (46) and ST1326 was shown to possess antitumour effects in leukemia and lymphoma $(47,48)$. The development of etomoxir has been stopped due to its high toxicity to heart and skeletal muscles. Further research is needed to explore the therapeutic potential of ST1326 since the inactivation of CPT1A in the long term may be associated with high risk of serious liver damage.

\section{Lipid metabolism in relation to inflammation}

Altered lipid metabolism and local immunosuppression in the tumour microenvironment are typical hallmarks of cancer. The main focus in this section is the crosstalk between these two features in the context of liver cancer. We have a particular interest in the metabolic signature and the role of specialized proresolving lipid mediators (SPM) in the resolution of inflammation and immunosuppression as related to tumour-associated macrophages (TAMs) and their immune modulation of tumour microenvironment.

Indeed, cancer cells recruit nearby cells for their own sake. HCC emerges from chronic unresolved inflammation and $\mathrm{HCC}$ cells recruit massively TAMs as the main immunosuppressive cells in their microenvironment (49). TAMs are known for their role in tumour development, angiogenesis, invasion and metastasis. The shift in the role of TAMs is due to different metabolic changes in response to signals coming from the tumour itself or even from other immune cells. For this reason, two main isotypes of TAMs are distinguished: the classically activated M1 (antitumour-like macrophages) and the alternately activated M2 (protumour-like macrophages) (50).

The cell metabolism is largely modulated by mammalian target of rapamycin (mTOR) signaling, which is essential for many processes, including tumour development, and solid tumours are currently treated with rapamycin or its analogs. Two multiprotein complexes can be distinguished, the mTOR complex 1 (mTORC1) and the mTOR complex 2 (mTORC2), 
which function in regulating protein synthesis and cytoskeleton organization respectively (51, 52). These two complexes are activated through their cognate receptors leading to the activation of class 1 phosphatidylinositol 3-kinase (PI3K) and serine/threonine kinases (AKT 1/2/3), known as PI3K/AKT/mTOR axis $(53,54)$. mTORC1 is strongly linked to inflammation mediated by macrophages via regulating many inflammatory mediators such as NFkB (nuclear factor $\kappa \mathrm{B}$ ), Il-10 (interleukine 10), TGF- $\beta$ (transforming growth factor beta) and PD-L1 (programmed death-ligand 1) expression (55). mTORC2 is also thought to play a great role in macrophage polarization (switch between M1 and M2 macrophages) and inflammatory response regulation (56). For instance, the activation of mTORC1 sustains and promotes M2 activation of macrophages in cases involving tuberous sclerosis complex 1 (TSC1) and AKT kinases (57). TSC1 is a key modulator of macrophage polarization via mTOR-dependent and independent pathways $(58,59)$. However, in some cases where hypoxia is induced in TAM, the deletion of an important inhibitor of mTORC1, named REDD1 for regulated in development and DNA damage responses 1, can switch macrophages to a new metabolic phenotype -increased glycolysis- in order to inhibit the metastasis of the tumour $(46,58,59)$. Therefore, the activation of mTOR signaling pathway can have different effects giving it a great role in regulating the differentiation of monocytes and thus polarization of TAMs.

Understanding how TAMs respond to mTOR signaling and thus polarize accordingly is still challenging. It is noteworthy to mention that M2-polarized macrophages enhance their metabolism in a direction that favors FAO in order to sustain the continuous energy demand $(60,61)$ unlike M1-like macrophages which promote the de novo synthesis of fatty acid (62). For instance, the presence of polyunsaturated fatty acids (PUFAs) in the tumour microenvironment supports not only the survival and migration of cancer cells, but also the polarization of TAM $(50,63)$ where PUFAs function as potent agonists for peroxisome proliferator-activated receptor $\beta / \delta(\operatorname{PPAR} \beta / \delta)$. $\mathrm{PPAR} \beta / \delta$ is a ligand-activated transcription 
factor (TF) that regulates the expression of genes involved in M2 macrophage polarization (63). Hence, it favors the polarization of macrophages in the tumour microenvironment towards M2 phenotype to further enhance the tumour growth and development. Another example involves prostaglandin E2 (PGE2) which also plays a role in M2-like polarization by binding to different cell factors in order to activate an important TF called cAMP response elementbinding protein (CREB) that mediates the transcription of genes involved in M2 phenotype (64). PGE2 can also direct naïve T cells toward regulatory immunosuppressive T cells (Treg) by inducing FOXP3 (forkhead box P3) expression (65). On another note, Kang et al. (66) have very recently reported that polarization of macrophages toward the M2-like phenotype is controlled by mTOR-Semaphorin 6D-PPAR $\gamma$ reverse signaling through controlling fatty acid metabolism. Any defect in this signaling axis leads to impaired fatty acid uptake and metabolic reprogramming, and therefore dysregulation in polarization. Finally, CG33, an antibody targeting the heparan sulfate proteoglycan Glypican 3 (GPC3) is currently in clinical phase I trials to treat advanced HCC $(67,68)$. GPC3 is supposed to favor M2-polarized TAM recruitment (61) macrophages to M2-like (64). Their synthesis can be inhibited by targeting microsomal PGE2 synthase 1 (mPGES1) and cyclooxygenase-2 (COX2) and as a result M2 to M1 polarization of TAMs is promoted in different cancer models $(69,70,71)$.

The second aspect of immunomodulation is related to the action of lipid mediators SPM, which are a family of arachidonic acid- and omega-3 polyunsaturated fatty acid-derived lipid mediators generated via the actions of some enzymes such as the lipoxygenases (ALOX) (72). Their role is to counteract the action of prostaglandins and to limit the effects of inflammation in various pathogenic conditions, of which cancer. The synthesis of some SPM is triggered by the action of aspirins, e.g. Aspirin Triggered-lipoxins (AT-LX or epi-lipoxins) or AT-resolvins. 
The mechanisms related to the potency of SPM to reduce the risk of cancer progression are starting to unfold (73). We were among the first to show that the proresolution actions of SPMs is mediated by their potential to induce the phagocytic capabilities of macrophages (72). In addition of modulating the phagocytosis, these SPM seems to alter the uptake of lipids by macrophages and probably modulating their immunosuppressive impact in tumour microenvironment (74) (Figure 4).

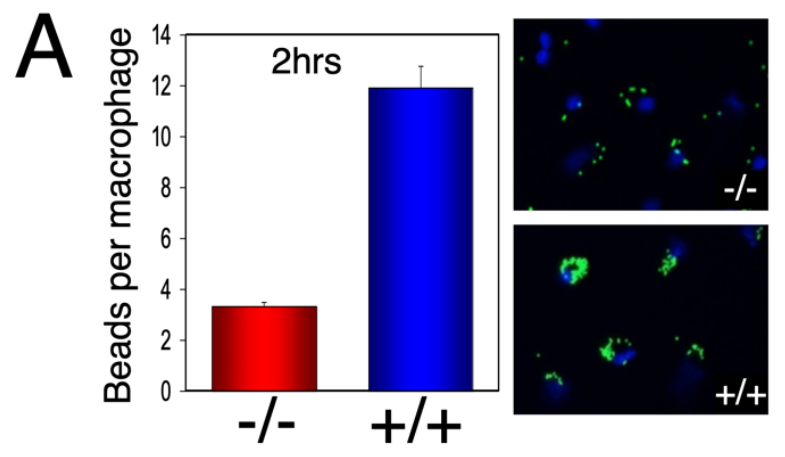

ALOX12
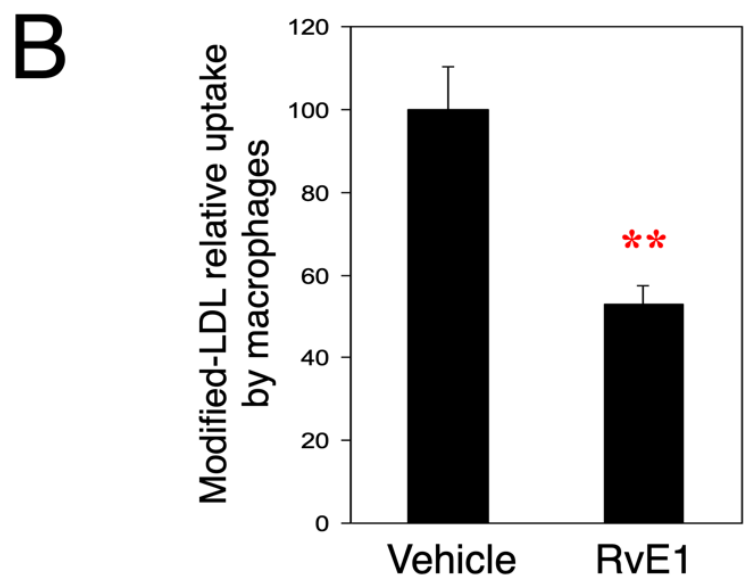

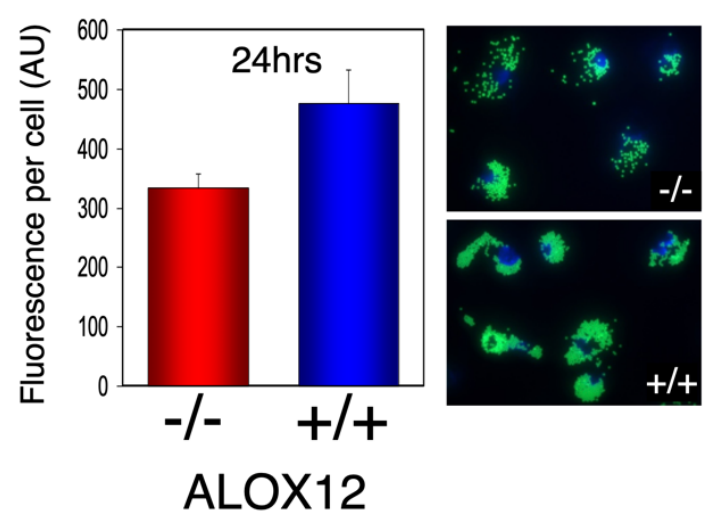

Resolvin E1

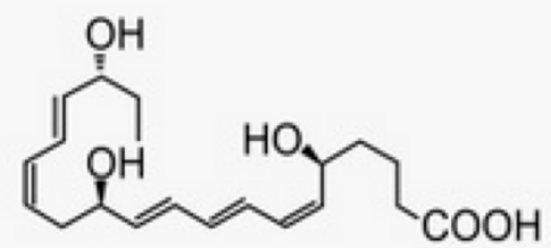

Figure 4. Modulation of macrophage activities related to phagocytosis (A) and lipid uptake (B) by SPM. (A) Assessment of phagocytosis of green fluorescent microspheres by macrophages lacking (-/-) or not $(+/+)$ the expression of 12-lipoxygenase (ALOX12), enzyme involved in generating many SPMs. The uptake was evaluated after 2 and 24 hours of 
incubations. (B) Modified lipoprotein (fluorescent acetylated-LDL) uptake by macrophages treated with resolvin E1 (RvE1) compared to controls (vehicle). ${ }^{* *} \mathrm{p}<0,01$.

These properties are becoming more relevant in the context of cellular damages linked to cytotoxic treatment in cancer patients. In fact, therapy- generated cell debris could inadvertently stimulate inflammation and growth of dormant tumour cells or small tumours. Debris-stimulated tumour cells were shown to be inhibited by some SPMs, namely resolvin $\mathrm{D} 1$ (RvD1), RvD2, or RvE1 by enhancing clearance of debris via macrophage phagocytosis in multiple tumour types (73). The results from this study highlight a novel approach of enhancing the endogenous clearance of tumour cell debris to prevent tumour growth and recurrence.

Moreover, the role of low-dose aspirin in resolution of cancer was shown to be dependent on resolving-receptor and that treatment of mice carrying Lewis lung carcinoma (LLC) with ATLXA4 and AT-RvD1 and 3 inhibited tumour growth by stimulating macrophage phagocytosis of the tumour cell debris generated by chemotherapy and by suppressing proinflammatory cytokines secretion by macrophages (75). Interestingly, the doses of AT-SPM administered in this LLC mouse model were much lower (more than a thousand-fold) than the doses of aspirin necessary to trigger a similar in vivo response. This makes these AT-SPM more powerful chemopreventive or antitumour treatment than aspirin, with potentially less risk, but this remains to be evaluated in humans.

To conclude, using specialized proresolving lipid mediators to enhance endogenous clearance of tumour cell debris by macrophages may be a beneficial approach to complement cytotoxic cancer therapies. Also, altering lipid metabolism in TAMs may be a promising target in cancer therapy. Modulating specific metabolic enzymes to allow the switch from M2 to M1 macrophages may be a more adapted approach to obtain anti-tumoural macrophages instead of 
eradicating altogether these cells. Thus, reducing the immunosuppressive ability of macrophages and enhancing their anti-tumoural activity to lead to a better response to chemotherapy or even immunotherapy (50).

\section{New treatment strategies targeting the lipid metabolism for HCC treatment}

Lipid metabolism is now considered as a major metabolic pathway involved in the progression of cancer. The production of lipids is necessary not only for DNA and proteins, but also for promoting cancer cell growth and proliferation. Lipids are known for their important structural role as they are the building blocks for membranes. They also function as signaling molecules in cancer and can be used for post-translational modifications of proteins (76). For these reasons, targeting lipid metabolism is considered as a promising approach when looking for new therapeutic ways to cure cancer.

Several studies have focused on the inhibition of enzymes of the FA biosynthesis pathway in an attempt to block cancer cell growth and have been reviewed in $(77,78,79)$ and are summarized in Table 1. Some are already on clinical trials. Among them, the fatty acid synthase (FASN), acetyl-CoA carboxylase (ACC) and stearoyl-CoA desaturase (SCD) have been pharmacologically targeted to inhibit lipid synthesis. For instance, FASN inhibitors (C75 and C247 or C93 and C95) used in mouse models exhibited chemopreventive effects in breast cancer (80) and reduced the induction of lung tumourigenesis (81). Moreover, targeting ACC and SCD were efficient to limit the growth and proliferation of cancer cells $(22,82)$. The ATPcitrate lyase (ACLY) catalyzes the production of acetyl-CoA from citrate during FA synthesis and its inhibition by SB-204990 has decreased the rates of hepatic cholesterol and FA syntheses (83). ACLY plays also a key role in the regulation of histone acetylation thereby linking the lipid metabolism to the regulation of gene expression (84). 
It has been known for a long time that there is an accumulation of cholesterol in cancerous tissues, in addition to an increased FA biosynthesis. Cholesterol, like TGs, is an essential lipid for cell viability, not only because it is a component of cell membrane fluidity but also as a precursor of many hormones (estrogens, androgens, progesterone, vitamins) and steroids. It is supplied by exogenous diet and cellular synthetic pathways. Hypercholesterolemia is usually treated by inhibiting the rate-limiting step of the cholesterol biosynthesis catalyzed by the HMGCR with statins. In recent studies, rosuvastatin was proven to prevent the development of HCC associated with NAFLD in mice and improves the hepatic background and thus can be used as a preventive drug for HCC development (85). Also, fluvastatin - together with sorafenib (a multikinase inhibitor) - had a synergistic anti-tumour efficacy in HCC which resulted in inhibiting cancer cell proliferation and promoting apoptosis (86).

There is a more promising evidence that statins could decrease the risk of HCC. This is discussed more in details in the review by Alipour et al. (Alipour et al, submitted jointly to this review). For instance, many observational studies done in high-risk areas such as Taiwan (87, $88,89,90)$ shows that the use of statins reduces the risk of HCC. El-Serag HB et al. (91), who observed a cohort of patients with diabetes, concluded that the use of statins significantly reduced the risk of HCC. The role of statins in reducing the HCC risk was confirmed when evaluating patients in the U.S, which is a low-risk HCC area (92). Another study recorded very promising results in a randomized controlled trial of pravastatin in patients having advanced HCC (93). They observed a significant prolonged survival of these patients upon treatment with $40 \mathrm{mg} /$ day of pravastatin compared to the non-treated ones (18 months' median survival in the pravastatin group compared to the control group which was 9 months; $\mathrm{P}=0.006$ ), therefore suggesting its value as an auxiliary treatment.

It is important to mention that inhibition of cholesterol synthesis by statins can lead to a restorative feedback loop mediated by the sterol regulatory element binding protein 2 
(SREBP2), making the anticancer effects of these drugs less effective. Indeed SREBP is a TF and master regulator of lipid biogenesis (94). It regulates the rate-limiting enzyme for cholesterol synthesis -HMGCR-and also the low-density lipoprotein receptor (LDLR) leading to cellular uptake of LDL and the depletion of serum cholesterol levels (95). Consequently, targeting SREBP2 was shown to effectively suppress the feedback activation loop triggered by statin treatment, widening the therapeutic window to include tumours otherwise unresponsive to statins (96).

Moreover, any atypical activation can lead to fatty liver disease and possibly cancer development (97). During angiogenesis, lipid metabolism is further enhanced and hence SREBP is activated by endothelial cells in response to vascular endothelial growth factor (VEGF) (98). However, treatment with a potent inhibitor of SREBP, 25-hydroxycholesterol (25-HC), prevented the migration and proliferation induced by VEGF in these endothelial cells (98). Therefore, SREBP2 seems to be an attractive and novel target which can be used in combination therapies with statins.

Furthermore, the epigenetic inhibitor MI-2 exhibits anti glioma activity (99), that could extend to tumours not harboring the H3K27M mutation of Histone 3. Indeed, if MI-2 was originally described as inhibiting menin, an essential component of the histone methyltransferase complex, it was recently suggested that lanosterol synthase (LSS) would be the real target of MI-2 in the case of isolated diffuse intrinsic pontine glioma (DIPG) cell treatment (100). LSS catalyzes the complex conversion of (S)-2,3-oxidosqualene in lanosterol, the first steroidal intermediate of the cholesterol biosynthesis. LSS can also catalyze the shunt pathway from (S)-2,3-oxidosqualene to lead to 24(S),25-epoxycholesterol (24,25-EC), a liver $\mathrm{X}$ receptor (LXR) agonist. MI-2 induces 24,25-EC accumulation and upregulation of the LXR target, at the detriment of cholesterol synthesis, similarly to RO-48-8071, a known LSS inhibitor (101). The final outcome is cell death and addition of cholesterol reverses the cell 
toxicity induced by RO-48-8071, thus confirming the role of cholesterol blocking in limiting cancer progression. LSS certainly deserves more attention in the context of drug research to treat HCC.

Targeting lipid metabolism is a promising therapeutic approach that needs to be extensively studied and explored. Thanks to modern technology, different inhibitors for different pathways were brought to light and are being studied in preclinical and clinical trials. Some of them are already approved and being used for treatment of diseases such as hyperlipidemia, diabetes or other metabolic syndromes. However, more effort is needed to fully understand the behavior of cancer cells and the way in which they escape different defense mechanisms.

\section{Aspirin in $\mathrm{HCC}$}

In addition to triggering the production of some specialized immunomodulatory SPMs, aspirin connection to cancer has been addressed in different perspectives. A chemopreventive role has been attributed to aspirin initially in colorectal cancer (CRC) (102) making it one of the promising anti-cancer drugs. This is supported by several studies, whether clinical or epidemiological, which were done over the last decades (103, 104, 105). Very recently, Yang $\mathrm{G}$ et al. (106) reported that aspirin inhibited the cancer growth by targeting an important $\mathrm{TF}$, the NFкB. Aspirin could suppress the abnormal lipid metabolism in HepG2 and Huh7 liver cancer cell lines in a dose dependent manner. The action of this drug was clearly through inhibiting an essential enzyme in the lipid metabolism, the Acyl-CoA synthetase long-chain family member 1 (ACSL1) at both mRNA and protein levels. Therefore, the potential role that could be played by aspirin in HCC would be through suppressing the abnormal lipid metabolism by abrogating the NFkB-ACSL1 signaling pathway.

Moreover, aspirin when combined with sorafenib to treat sorafenib-resistant HCC cells (HCC-LM3 and Huh7-R) increased the cellular inhibition and apoptosis of these resistant cells 
in vitro and in vivo (107) without having side effects such as weight loss, hepatotoxicity or inflammation. Hence, the conclusion of this study is that aspirin can overcome the resistance to sorafenib and the combination of sorafenib and aspirin can be a promising therapeutic option for HCC. Similar effect has been observed in Navitoclax-resistant HCC cell lines, (108). Navitoclax is an inhibitor of the antiapoptotic proteins Bcl-2/Bcl-xL (B-Cell Leukemia/Lymphoma-2/-extra large) with strong antitumour activities in different cancers, but with a low binding affinity to Mcl-1 (Induced myeloid leukemia cell differentiation protein 1), a member of the Bcl-2 family which is overexpressed in $\operatorname{HCC}(109,110)$. Aspirin treatment suppressed Mcl-1 expression and enhanced the inhibition of cell viability with induction of apoptosis in HCC cell lines, HepG2 and BEL-7402. Furthermore, other in vitro and in vivo studies assured the role of aspirin in overcoming treatment resistances and enhancing the IFN$\alpha$ effect in the treatment of HCC through activating the STAT1 gene that is known for exerting its antiproliferative and proapoptotic effect by mediating tumour cell response to IFN- $\alpha$ (111).

Some of the HCC tumours are unresectable and the only available method of treating such tumours is through transarterial chemoemobilization (TACE) (112). The response to this treatment differs between patients; for example, patients in the intermediate stage of the disease show better median survival (16-20 months) than those in the advanced stages of HCC ( 8 months) (113). However, when this treatment is repeated several times, its efficacy is diminished and the patients enter the state of TACE failure/refractoriness (114). So in this case, multiple nodules will be scattered in the liver, and the nontumoural part of the liver will be damaged because of the multiple use of TACE leading in the end to a decrease in the survival time of the patients (115). Because of all these limitations associated with TACE, it was of a great need to look for some alternative, probably combination therapies, to decrease the risks of failure and improve the survival outcome of patients in such treatments. Li et al. (116) were the first to evaluate the combined effects of aspirin and TACE therapy in treating patients 
suffering from HCC. They observed that the auxiliary aspirin treatment with TACE in cases of unresectable HCC could improve the overall survival in such patients without having side effects like fatal bleeding.

\section{Conclusion:}

Enhanced lipogenesis in highly proliferative tumour cells provides the building block materials, signaling molecules and bioactive mediators to ensure their growth, proliferation and persistence. The progression of HCC is associated with complex metabolic reprogramming, as well as immunosuppressive drive provided by TAMs and mediated by bioactive lipid mediators.

By dissecting the diverse lipid metabolic network and highlighting many of its cancer associated signatures, we have discussed how the lipidome can be malleable to interfere with oncogenesis.

Several established drugs targeting the lipid metabolism are showing promising anti-cancer properties and may emerge as highly valuable choices for new oncology indications. Others may be coming out of the dark for the use in a drug combination approach to minimize the adaptive metabolic reprogramming of cancer cells and/or to improve the effectiveness of the ongoing immunotherapeutic interventions. Finally, the bioactive lipids appear to hold great promise in our apprehension of the lipid involvement in immunosuppression and oncogenesis and can ultimately be considered as a new treatment modality that deserves to be appraised in cancer.

\section{Acknowledgements:}

This work was supported by the American Heart Association, the Association Cassandra contre les Leucémies et les Cancers Pédiatriques, the Institut National de la Santé et de la 
Recherche Médicale-INSERM, the Centre National de la Recherche Scientifique- CNRS, and the University of Bordeaux. The figures were generated with images from SMART- Servier medical art (https://smart.servier.com/). MA was awarded a scholarship from the Lebanese University.

Bibliography

(1) Hanahan, D., and Weinberg, R. A. (2011) Hallmarks of Cancer: The Next Generation. Cell 144, 646-674.

(2) International Agency for Research on Cancer. (2014) World cancer report 2014.

(3) de Martel, C., Maucort-Boulch, D., Plummer, M., and Franceschi, S. (2015) World-wide relative contribution of hepatitis $\mathrm{B}$ and $\mathrm{C}$ viruses in hepatocellular carcinoma: HEPATOLOGY, Vol. XX, No. X, 2015. Hepatology 62, 1190-1200.

(4) El-Serag, H. B. (2012) Epidemiology of Viral Hepatitis and Hepatocellular Carcinoma. Gastroenterology 142, 1264-1273.e1.

(5) Baffy, G., Brunt, E. M., and Caldwell, S. H. (2012) Hepatocellular carcinoma in nonalcoholic fatty liver disease: An emerging menace. Journal of Hepatology 56, 1384-1391.

(6) Beyoğlu, D., and Idle, J. R. (2013) The metabolomic window into hepatobiliary disease. Journal of Hepatology 59, 842-858.

(7) Vander Heiden, M. G., Cantley, L. C., and Thompson, C. B. (2009) Understanding the Warburg Effect: The Metabolic Requirements of Cell Proliferation. Science 324, 1029-1033.

(8) Pietrocola, F., Galluzzi, L., Bravo-San Pedro, J. M., Madeo, F., and Kroemer, G. (2015) Acetyl coenzyme A: a central metabolite and second messenger. Cell Metab. 21, 805-821.

(9) Shi, L., and Tu, B. P. (2015) Acetyl-CoA and the regulation of metabolism: mechanisms and consequences. Curr. Opin. Cell Biol. 33, 125-131. 
(10) Ma, Y., Temkin, S. M., Hawkridge, A. M., Guo, C., Wang, W., Wang, X.-Y., and Fang, X. (2018) Fatty acid oxidation: An emerging facet of metabolic transformation in cancer. Cancer Lett. 435, 92-100.

(11) Kim, J.-A., and Yeom, Y. I. (2018) Metabolic Signaling to Epigenetic Alterations in Cancer. Biomol Ther (Seoul) 26, 69-80.

(12) McGarry, J. D., and Foster, D. W. (1980) Regulation of Hepatic Fatty Acid Oxidation and Ketone Body Production. Annual Review of Biochemistry 49, 395-420.

(13) Catalina-Rodriguez, O., Kolukula, V. K., Tomita, Y., Preet, A., Palmieri, F., Wellstein, A., Byers, S., Giaccia, A. J., Glasgow, E., Albanese, C., and Avantaggiati, M. L. (2012) The mitochondrial citrate transporter, CIC, is essential for mitochondrial homeostasis. Oncotarget $3,1220-1235$.

(14) Wen, H., Lee, S., Zhu, W.-G., Lee, O.-J., Yun, S. J., Kim, J., and Park, S. (2019) Glucose-derived acetate and ACSS2 as key players in cisplatin resistance in bladder cancer. Biochim Biophys Acta Mol Cell Biol Lipids 1864, 413-421.

(15) Liu, D., Wong, C. C., Fu, L., Chen, H., Zhao, L., Li, C., Zhou, Y., Zhang, Y., Xu, W., Yang, Y., Wu, B., Cheng, G., Lai, P. B.-S., Wong, N., Sung, J. J. Y., and Yu, J. (2018) Squalene epoxidase drives NAFLD-induced hepatocellular carcinoma and is a pharmaceutical target. Science Translational Medicine 10, eaap9840.

(16) Brownsey, R. W., Boone, A. N., Elliott, J. E., Kulpa, J. E., and Lee, W. M. (2006) Regulation of acetyl-CoA carboxylase. Biochem. Soc. Trans. 34, 223-227.

(17) Koves, T. R., Ussher, J. R., Noland, R. C., Slentz, D., Mosedale, M., Ilkayeva, O., Bain, J., Stevens, R., Dyck, J. R. B., Newgard, C. B., Lopaschuk, G. D., and Muoio, D. M. (2008) Mitochondrial overload and incomplete fatty acid oxidation contribute to skeletal muscle insulin resistance. Cell Metab. 7, 45-56. 
(18) Bhalla, K., Hwang, B. J., Dewi, R. E., Twaddel, W., Goloubeva, O. G., Wong, K.-K., Saxena, N. K., Biswal, S., and Girnun, G. D. (2012) Metformin Prevents Liver Tumourigenesis by Inhibiting Pathways Driving Hepatic Lipogenesis. Cancer Prev Res 5, 544-552.

(19) Zakikhani, M., Dowling, R., Fantus, I. G., Sonenberg, N., and Pollak, M. (2006) Metformin Is an AMP Kinase-Dependent Growth Inhibitor for Breast Cancer Cells. Cancer Res 66, 10269-10273.

(20) Memmott, R. M., Mercado, J. R., Maier, C. R., Kawabata, S., Fox, S. D., and Dennis, P. A. (2010) Metformin Prevents Tobacco Carcinogen-Induced Lung Tumourigenesis. Cancer Prev Res 3, 1066-1076.

(21) Gerth, K., Bedorf, N., Irschik, H., Höfle, G., and Reichenbach, H. (1994) The soraphens: a family of novel antifungal compounds from Sorangium cellulosum (Myxobacteria). I. Soraphen A1 alpha: fermentation, isolation, biological properties. J. Antibiot. 47, 23-31.

(22) Beckers, A., Organe, S., Timmermans, L., Scheys, K., Peeters, A., Brusselmans, K., Verhoeven, G., and Swinnen, J. V. (2007) Chemical Inhibition of Acetyl-CoA Carboxylase Induces Growth Arrest and Cytotoxicity Selectively in Cancer Cells. Cancer Res 67, 81808187.

(23) Rysman, E., Brusselmans, K., Scheys, K., Timmermans, L., Derua, R., Munck, S., Veldhoven, P. P. V., Waltregny, D., Daniëls, V. W., Machiels, J., Vanderhoydonc, F., Smans, K., Waelkens, E., Verhoeven, G., and Swinnen, J. V. (2010) De novo Lipogenesis Protects Cancer Cells from Free Radicals and Chemotherapeutics by Promoting Membrane Lipid Saturation. Cancer Res 70, 8117-8126.

(24) Stoiber, K., Nagło, O., Pernpeintner, C., Zhang, S., Koeberle, A., Ulrich, M., Werz, O., Müller, R., Zahler, S., Lohmüller, T., Feldmann, J., and Braig, S. (2018) Targeting de novo lipogenesis as a novel approach in anti-cancer therapy. British Journal of Cancer 118, 43-51. 
(25) Guseva, N. V., Rokhlin, O. W., Glover, R. A., and Cohen, M. B. (2011) TOFA (5tetradecyl-oxy-2-furoic acid) reduces fatty acid synthesis, inhibits expression of AR, neuropilin-1 and Mcl-1 and kills prostate cancer cells independent of p53 status. Cancer Biol. Ther. 12, 80-85.

(26) Wang, C., Xu, C., Sun, M., Luo, D., Liao, D.-F., and Cao, D. (2009) Acetyl-CoA carboxylase-alpha inhibitor TOFA induces human cancer cell apoptosis. Biochem. Biophys. Res. Commun. 385, 302-306.

(27) Li, S., Qiu, L., Wu, B., Shen, H., Zhu, J., Zhou, L., Gu, L., and Di, W. (2013) TOFA suppresses ovarian cancer cell growth in vitro and in vivo. Molecular Medicine Reports 8, 373378.

(28) Luckman, S. P., Hughes, D. E., Coxon, F. P., Russell, R. G. G., and Rogers, M. J. (1998) Nitrogen-Containing Bisphosphonates Inhibit the Mevalonate Pathway and Prevent PostTranslational Prenylation of GTP-Binding Proteins, Including Ras. Journal of Bone and Mineral Research 13, 581-589.

(29) Gong, L., Altman, R. B., and Klein, T. E. (2011) Bisphosphonates pathway. Pharmacogenet Genomics 21, 50-53.

(30) Lanterna, C., Musumeci, A., Raccosta, L., Corna, G., Moresco, M., Maggioni, D., Fontana, R., Doglioni, C., Bordignon, C., Traversari, C., and Russo, V. (2016) The administration of drugs inhibiting cholesterol/oxysterol synthesis is safe and increases the efficacy of immunotherapeutic regimens in tumour-bearing mice. Cancer Immunol. Immunother. 65, 1303-1315.

(31) Wang, Y., Viscarra, J., Kim, S.-J., and Sul, H. S. (2015) Transcriptional regulation of hepatic lipogenesis. Nature Reviews Molecular Cell Biology 16, 678-689.

(32) Lu, G.-D., and Hooi, S. C. (2017) Lipid Metabolism in Liver Cancer. Updates in Liver Cancer, pp 49-67. 
(33) Beyoğlu, D., Imbeaud, S., Maurhofer, O., Bioulac-Sage, P., Zucman-Rossi, J., Dufour, J.-F., and Idle, J. R. (2013) Tissue metabolomics of hepatocellular carcinoma: Tumour energy metabolism and the role of transcriptomic classification. Hepatology 58, 229-238.

(34) Budhu, A., Roessler, S., Zhao, X., Yu, Z., Forgues, M., Ji, J., Karoly, E., Qin, L.-X., Ye, Q.-H., Jia, H.-L., Fan, J., Sun, H.-C., Tang, Z.-Y., and Wang, X. W. (2013) Integrated Metabolite and Gene Expression Profiles Identify Lipid Biomarkers Associated With Progression of Hepatocellular Carcinoma and Patient Outcomes. Gastroenterology 144, 10661075.e1.

(35) Chen, T., Xie, G., Wang, X., Fan, J., Qiu, Y., Zheng, X., Qi, X., Cao, Y., Su, M., Wang, X., Xu, L. X., Yen, Y., Liu, P., and Jia, W. (2011) Serum and Urine Metabolite Profiling Reveals Potential Biomarkers of Human Hepatocellular Carcinoma. Molecular \& Cellular Proteomics 10, M110.004945.

(36) Zeng, J., Yin, P., Tan, Y., Dong, L., Hu, C., Huang, Q., Lu, X., Wang, H., and Xu, G. (2014) Metabolomics Study of Hepatocellular Carcinoma: Discovery and Validation of Serum Potential Biomarkers by Using Capillary Electrophoresis-Mass Spectrometry. Journal of Proteome Research 13, 3420-3431.

(37) Chen, S., Yin, P., Zhao, X., Xing, W., Hu, C., Zhou, L., and Xu, G. (2013) Serum lipid profiling of patients with chronic hepatitis B, cirrhosis, and hepatocellular carcinoma by ultra fast LC/IT-TOF MS. ELECTROPHORESIS 34, 2848-2856.

(38) Li, Z., Guan, M., Lin, Y., Cui, X., Zhang, Y., Zhao, Z., and Zhu, J. (2017) Aberrant Lipid Metabolism in Hepatocellular Carcinoma Revealed by Liver Lipidomics. International Journal of Molecular Sciences 18, 2550.

(39) Lin, L., Ding, Y., Wang, Y., Wang, Z., Yin, X., Yan, G., Zhang, L., Yang, P., and Shen, H. (2017) Functional lipidomics: Palmitic acid impairs hepatocellular carcinoma development by modulating membrane fluidity and glucose metabolism. Hepatology 66, 432-448. 
(40) Carracedo, A., Cantley, L. C., and Pandolfi, P. P. (2013) Cancer metabolism: fatty acid oxidation in the limelight. Nat. Rev. Cancer 13, 227-232.

(41) Ma, Y., Temkin, S. M., Hawkridge, A. M., Guo, C., Wang, W., Wang, X.-Y., and Fang, X. (2018) Fatty acid oxidation: An emerging facet of metabolic transformation in cancer. Cancer Lett 435, 92-100.

(42) Lu, G.-D., Ang, Y. H., Zhou, J., Tamilarasi, J., Yan, B., Lim, Y. C., Srivastava, S., SaltoTellez, M., Hui, K. M., Shen, H.-M., Nguyen, L. N., Tan, B. C., Silver, D. L., and Hooi, S. C. (2015) CCAAT/enhancer binding protein $\alpha$ predicts poorer prognosis and prevents energy starvation-induced cell death in hepatocellular carcinoma. Hepatology 61, 965-978.

(43) Schafer, Z. T., Grassian, A. R., Song, L., Jiang, Z., Gerhart-Hines, Z., Irie, H. Y., Gao, S., Puigserver, P., and Brugge, J. S. (2009) Antioxidant and Oncogene Rescue of Metabolic Defects Caused by Loss of Matrix Attachment. Nature 461, 109-113.

(44) Carracedo, A., Weiss, D., Leliaert, A. K., Bhasin, M., de Boer, V. C. J., Laurent, G., Adams, A. C., Sundvall, M., Song, S. J., Ito, K., Finley, L. S., Egia, A., Libermann, T., GerhartHines, Z., Puigserver, P., Haigis, M. C., Maratos-Flier, E., Richardson, A. L., Schafer, Z. T., and Pandolfi, P. P. (2012) A metabolic prosurvival role for PML in breast cancer. J Clin Invest $122,3088-3100$.

(45) Zaugg, K., Yao, Y., Reilly, P. T., Kannan, K., Kiarash, R., Mason, J., Huang, P., Sawyer, S. K., Fuerth, B., Faubert, B., Kalliomäki, T., Elia, A., Luo, X., Nadeem, V., Bungard, D., Yalavarthi, S., Growney, J. D., Wakeham, A., Moolani, Y., Silvester, J., Ten, A. Y., Bakker, W., Tsuchihara, K., Berger, S. L., Hill, R. P., Jones, R. G., Tsao, M., Robinson, M. O., Thompson, C. B., Pan, G., and Mak, T. W. (2011) Carnitine palmitoyltransferase 1C promotes cell survival and tumour growth under conditions of metabolic stress. Genes Dev 25, 10411051. 
(46) Samudio, I., Harmancey, R., Fiegl, M., Kantarjian, H., Konopleva, M., Korchin, B., Kaluarachchi, K., Bornmann, W., Duvvuri, S., Taegtmeyer, H., and Andreeff, M. (2010) Pharmacologic inhibition of fatty acid oxidation sensitizes human leukemia cells to apoptosis induction. $J$ Clin Invest 120, 142-156.

(47) Ricciardi, M. R., Mirabilii, S., Allegretti, M., Licchetta, R., Calarco, A., Torrisi, M. R., Foà, R., Nicolai, R., Peluso, G., and Tafuri, A. (2015) Targeting the leukemia cell metabolism by the CPT1a inhibition: functional preclinical effects in leukemias. Blood 126, 1925-1929.

(48) Pacilli, A., Calienni, M., Margarucci, S., D’Apolito, M., Petillo, O., Rocchi, L., Pasquinelli, G., Nicolai, R., Koverech, A., Calvani, M., Peluso, G., and Montanaro, L. (2013) Carnitine-Acyltransferase System Inhibition, Cancer Cell Death, and Prevention of MycInduced Lymphomagenesis. J Natl Cancer Inst 105, 489-498.

(49) Lewis, M., and Merched, A. (2014) Tumor-Associated Macrophages, Inflammation and Pathogenesis of Hepatocellular Carcinoma. J Mol Genet Med 08.

(50) Mazzone, M., Menga, A., and Castegna, A. (2018) Metabolism and TAM functions-it takes two to tango. The FEBS Journal 285, 700-716.

(51) Zarogoulidis, P., Lampaki, S., Turner, J. F., Huang, H., Kakolyris, S., Syrigos, K., and Zarogoulidis, K. (2014) mTOR pathway: A current, up-to-date mini-review (Review). Oncol Lett 8, 2367-2370.

(52) Düvel, K., Yecies, J. L., Menon, S., Raman, P., Lipovsky, A. I., Souza, A. L., Triantafellow, E., Ma, Q., Gorski, R., Cleaver, S., Vander Heiden, M. G., MacKeigan, J. P., Finan, P. M., Clish, C. B., Murphy, L. O., and Manning, B. D. (2010) Activation of a metabolic gene regulatory network downstream of mTOR complex 1. Mol. Cell 39, 171-183.

(53) Luo, L., Wall, A. A., Yeo, J. C., Condon, N. D., Norwood, S. J., Schoenwaelder, S., Chen, K. W., Jackson, S., Jenkins, B. J., Hartland, E. L., Schroder, K., Collins, B. M., Sweet, 
M. J., and Stow, J. L. (2014) Rab8a interacts directly with PI3K $\gamma$ to modulate TLR4-driven PI3K and mTOR signalling. Nat Commun 5, 4407.

(54) Shimobayashi, M., and Hall, M. N. (2014) Making new contacts: the mTOR network in metabolism and signalling crosstalk. Nature Reviews Molecular Cell Biology 15, 155-162.

(55) Katholnig, K., Linke, M., Pham, H., Hengstschläger, M., and Weichhart, T. (2013) Immune responses of macrophages and dendritic cells regulated by mTOR signaling. Biochem Soc Trans 41, 927-933.

(56) Huang, S. C.-C., Smith, A. M., Everts, B., Colonna, M., Pearce, E. L., Schilling, J. D., and Pearce, E. J. (2016) Metabolic Reprogramming Mediated by the mTORC2-IRF4 Signaling Axis Is Essential for Macrophage Alternative Activation. Immunity 45, 817-830.

(57) Arranz, A., Doxaki, C., Vergadi, E., Martinez de la Torre, Y., Vaporidi, K., Lagoudaki, E. D., Ieronymaki, E., Androulidaki, A., Venihaki, M., Margioris, A. N., Stathopoulos, E. N., Tsichlis, P. N., and Tsatsanis, C. (2012) Akt1 and Akt2 protein kinases differentially contribute to macrophage polarization. Proc Natl Acad Sci U S A 109, 9517-9522.

(58) Covarrubias, A. J., Aksoylar, H. I., and Horng, T. (2015) Control of macrophage metabolism and activation by mTOR and Akt signaling. Semin Immunol 27, 286-296.

(59) Zhu, L., Yang, T., Li, L., Sun, L., Hou, Y., Hu, X., Zhang, L., Tian, H., Zhao, Q., Peng, J., Zhang, H., Wang, R., Yang, Z., Zhang, L., and Zhao, Y. (2014) TSC1 controls macrophage polarization to prevent inflammatory disease. Nat Commun 5, 1-13.

(60) O’Neill, L. A. J., and Hardie, D. G. (2013) Metabolism of inflammation limited by AMPK and pseudo-starvation. Nature 493, 346-355.

(61) Huang, S. C.-C., Everts, B., Ivanova, Y., O’Sullivan, D., Nascimento, M., Smith, A. M., Beatty, W., Love-Gregory, L., Lam, W. Y., O’Neill, C. M., Yan, C., Du, H., Abumrad, N. A., Urban, J. F., Artyomov, M. N., Pearce, E. L., and Pearce, E. J. (2014) Cell-intrinsic lysosomal lipolysis is essential for macrophage alternative activation. Nat Immunol 15, 846-855. 
(62) Kelly, B., and O’Neill, L. A. (2015) Metabolic reprogramming in macrophages and dendritic cells in innate immunity. Cell Res 25, 771-784.

(63) Schumann, T., Adhikary, T., Wortmann, A., Finkernagel, F., Lieber, S., Schnitzer, E., Legrand, N., Schober, Y., Nockher, W. A., Toth, P. M., Diederich, W. E., Nist, A., Stiewe, T., Wagner, U., Reinartz, S., Müller-Brüsselbach, S., and Müller, R. (2015) Deregulation of $\mathrm{PPAR} \beta / \delta$ target genes in tumour-associated macrophages by fatty acid ligands in the ovarian cancer microenvironment. Oncotarget 6, 13416-13433.

(64) Barminko, J. A., Nativ, N. I., Schloss, R., and Yarmush, M. L. (2014) Fractional Factorial Design to Investigate Stromal Cell Regulation of Macrophage Plasticity. Biotechnol Bioeng 111, 2239-2251.

(65) Nakanishi, M., and Rosenberg, D. W. (2013) Multifaceted roles of PGE2 in inflammation and cancer. Semin Immunopathol 35, 123-137.

(66) Kang, S., Nakanishi, Y., Kioi, Y., Okuzaki, D., Kimura, T., Takamatsu, H., Koyama, S., Nojima, S., Nishide, M., Hayama, Y., Kinehara, Y., Kato, Y., Nakatani, T., Shimogori, T., Takagi, J., Toyofuku, T., and Kumanogoh, A. (2018) Semaphorin 6D reverse signaling controls macrophage lipid metabolism and anti-inflammatory polarization. Nat Immunol 19, 561-570.

(67) Zhu, A. X., Gold, P. J., El-Khoueiry, A. B., Abrams, T. A., Morikawa, H., Ohishi, N., Ohtomo, T., and Philip, P. A. (2013) First-in-Man Phase I Study of GC33, a Novel Recombinant Humanized Antibody Against Glypican-3, in Patients with Advanced Hepatocellular Carcinoma. Clin Cancer Res 19, 920-928.

(68) Ikeda, M., Ohkawa, S., Okusaka, T., Mitsunaga, S., Kobayashi, S., Morizane, C., Suzuki, I., Yamamoto, S., and Furuse, J. (2014) Japanese phase I study of GC33, a humanized antibody against glypican-3 for advanced hepatocellular carcinoma. Cancer Science 105, 455462. 
(69) Heusinkveld, M., Steenwijk, P. J. de V. van, Goedemans, R., Ramwadhdoebe, T. H., Gorter, A., Welters, M. J. P., Hall, T. van, and Burg, S. H. van der. (2011) M2 Macrophages Induced by Prostaglandin E2 and IL-6 from Cervical Carcinoma Are Switched to Activated M1 Macrophages by CD4+ Th1 Cells. The Journal of Immunology 187, 1157-1165.

(70) Prima, V., Kaliberova, L. N., Kaliberov, S., Curiel, D. T., and Kusmartsev, S. (2017) COX2/mPGES1/PGE2 pathway regulates PD-L1 expression in tumour-associated macrophages and myeloid-derived suppressor cells. PNAS 114, 1117-1122.

(71) Nakanishi, Y., Nakatsuji, M., Seno, H., Ishizu, S., Akitake-Kawano, R., Kanda, K., Ueo, T., Komekado, H., Kawada, M., Minami, M., and Chiba, T. (2011) COX-2 inhibition alters the phenotype of tumour-associated macrophages from M2 to M1 in Apc Min/+ mouse polyps. Carcinogenesis 32, 1333-1339.

(72) Merched, A. J., Ko, K., Gotlinger, K. H., Serhan, C. N., and Chan, L. (2008) Atherosclerosis: evidence for impairment of resolution of vascular inflammation governed by specific lipid mediators. FASEB J. 22, 3595-3606.

(73) Sulciner, M. L., Gartung, A., Gilligan, M. M., Serhan, C. N., and Panigrahy, D. (2018) Targeting lipid mediators in cancer biology. Cancer Metastasis Rev. 37, 557-572.

(74) Merched, A. J., Serhan, C. N., and Chan, L. (2011) Nutrigenetic disruption of inflammation-resolution homeostasis and atherogenesis. J Nutrigenet Nutrigenomics 4, 12-24.

(75) Gilligan, M. M., Gartung, A., Sulciner, M. L., Norris, P. C., Sukhatme, V. P., Bielenberg, D. R., Huang, S., Kieran, M. W., Serhan, C. N., and Panigrahy, D. (2019) Aspirintriggered proresolving mediators stimulate resolution in cancer. PNAS 116, 6292-6297.

(76) Baenke, F., Peck, B., Miess, H., and Schulze, A. (2013) Hooked on fat: the role of lipid synthesis in cancer metabolism and tumour development. Disease Models \& Mechanisms 6, 1353-1363. 
(77) Abramson, H. N. (2011) The Lipogenesis Pathway as a Cancer Target. J. Med. Chem. $54,5615-5638$.

(78) Menendez, J. A., and Lupu, R. (2007) Fatty acid synthase and the lipogenic phenotype in cancer pathogenesis. Nat Rev Cancer 7, 763-777.

(79) Santos, C. R., and Schulze, A. (2012) Lipid metabolism in cancer. The FEBS Journal 279, 2610-2623.

(80) Alli, P. M., Pinn, M. L., Jaffee, E. M., McFadden, J. M., and Kuhajda, F. P. (2005) Fatty acid synthase inhibitors are chemopreventive for mammary cancer in neu- $\mathrm{N}$ transgenic mice. Oncogene 24, 39-46.

(81) Orita, H., Coulter, J., Tully, E., Kuhajda, F. P., and Gabrielson, E. (2008) Inhibiting Fatty Acid Synthase for Chemoprevention of Chemically Induced Lung Tumours. Clin Cancer Res 14, 2458-2464.

(82) Fritz, V., Benfodda, Z., Rodier, G., Henriquet, C., Iborra, F., Avancès, C., Allory, Y., Taille, A. de la, Culine, S., Blancou, H., Cristol, J. P., Michel, F., Sardet, C., and Fajas, L. (2010) Abrogation of De novo Lipogenesis by Stearoyl-CoA Desaturase 1 Inhibition Interferes with Oncogenic Signaling and Blocks Prostate Cancer Progression in Mice. Mol Cancer Ther 9, $1740-1754$.

(83) Pearce, N. J., Yates, J. W., Berkhout, T. A., Jackson, B., Tew, D., Boyd, H., Camilleri, P., Sweeney, P., Gribble, A. D., Shaw, A., and Groot, P. H. E. (1998) The role of ATP citratelyase in the metabolic regulation of plasma lipids. Biochem $J 334,113-119$.

(84) Wellen, K. E., Hatzivassiliou, G., Sachdeva, U. M., Bui, T. V., Cross, J. R., and Thompson, C. B. (2009) ATP-Citrate Lyase Links Cellular Metabolism to Histone Acetylation. Science 324, 1076-1080.

(85) Yokohama, K., Fukunishi, S., Ii, M., Nakamura, K., Ohama, H., Tsuchimoto, Y., Asai, A., Tsuda, Y., and Higuchi, K. (2016) Rosuvastatin as a potential preventive drug for the 
development of hepatocellular carcinoma associated with non-alcoholic fatty liver disease in mice. International Journal of Molecular Medicine 38, 1499-1506.

(86) Cheng, Y., Luo, R. C., Zheng, H., Wang, B., Liu, Y., Liu, D. L., Chen, J., Xu, W., Li, A., and Zhu, Y. (2017) Synergistic anti-tumour efficacy of sorafenib and fluvastatin in hepatocellular carcinoma. Oncotarget 8, 23265-23276.

(87) Chiu, H.-F., Ho, S.-C. M., Chen, C.-C., and Yang, C.-Y. (2011) Statin Use and the Risk of Liver Cancer: A Population-Based Case-Control Study. Journal of Gastroenterology 106, 894-898.

(88) Tsan, Y.-T., Lee, C.-H., Ho, W.-C., Lin, M.-H., Wang, J.-D., and Chen, P.-C. (2013) Statins and the Risk of Hepatocellular Carcinoma in Patients With Hepatitis C Virus Infection. Journal of Clinical Oncology.

(89) Tsan, Y.-T., Lee, C.-H., Wang, J.-D., and Chen, P.-C. (2012) Statins and the Risk of Hepatocellular Carcinoma in Patients With Hepatitis B Virus Infection. JCO 30, 623-630.

(90) Friis, S., Poulsen, A. H., Johnsen, S. P., McLaughlin, J. K., Fryzek, J. P., Dalton, S. O., Sørensen, H. T., and Olsen, J. H. (2005) Cancer risk among statin users: A population-based cohort study. International Journal of Cancer 114, 643-647.

(91) El-Serag, H. B., Johnson, M. L., Hachem, C., and Morgana, R. O. (2009) Statins Are Associated With a Reduced Risk of Hepatocellular Carcinoma in a Large Cohort of Patients With Diabetes. Gastroenterology 136, 1601-1608.

(92) McGlynn, K. A., Divine, G. W., Sahasrabuddhe, V. V., Engel, L. S., VanSlooten, A., Wells, K., Yood, M. U., and Alford, S. H. (2014) Statin use and risk of hepatocellular carcinoma in a U.S. population. Cancer Epidemiol 38, 523-527.

(93) Kawata, S., Yamasaki, E., Nagase, T., Inui, Y., Ito, N., Matsuda, Y., Inada, M., Tamura, S., Noda, S., Imai, Y., and Matsuzawa, Y. (2001) Effect of pravastatin on survival in patients 
with advanced hepatocellular carcinoma. A randomized controlled trial. Br J Cancer 84, 886891.

(94) Bengoechea-Alonso, M. T., and Ericsson, J. (2007) SREBP in signal transduction: cholesterol metabolism and beyond. Current Opinion in Cell Biology 19, 215-222.

(95) Brown, M. S., and Goldstein, J. L. (2009) Cholesterol feedback: from Schoenheimer's bottle to Scap's MELADL. J. Lipid Res. 50 Suppl, S15-27.

(96) Pandyra, A. A., Mullen, P. J., Goard, C. A., Ericson, E., Sharma, P., Kalkat, M., Yu, R., Pong, J. T., Brown, K. R., Hart, T., Gebbia, M., Lang, K. S., Giaever, G., Nislow, C., Moffat, J., and Penn, L. Z. (2015) Genome-wide RNAi analysis reveals that simultaneous inhibition of specific mevalonate pathway genes potentiates tumour cell death. Oncotarget 6, 26909-26921.

(97) Shao, W., and Espenshade, P. J. (2012) Expanding Roles for SREBP in Metabolism. Cell Metabolism 16, 414-419.

(98) Zhou Rui-Hai, Yao Min, Lee Tzong-Shyuan, Zhu Yi, Martins-Green Manuela, and Shyy John Y.-J. (2004) Vascular Endothelial Growth Factor Activation of Sterol Regulatory Element Binding Protein. Circulation Research 95, 471-478.

(99) Grembecka, J., He, S., Shi, A., Purohit, T., Muntean, A. G., Sorenson, R. J., Showalter, H. D., Murai, M. J., Belcher, A. M., Hartley, T., Hess, J. L., and Cierpicki, T. (2012) MeninMLL inhibitors reverse oncogenic activity of MLL fusion proteins in leukemia. Nat. Chem. Biol. 8, 277-284.

(100) Phillips, R. E., Yang, Y., Smith, R. C., Thompson, B. M., Yamasaki, T., SotoFeliciano, Y. M., Funato, K., Liang, Y., Garcia-Bermudez, J., Wang, X., Garcia, B. A., Yamasaki, K., McDonald, J. G., Birsoy, K., Tabar, V., and Allis, C. D. (2019) Target identification reveals lanosterol synthase as a vulnerability in glioma. PNAS 116, 7957-7962. (101) Morand, O. H., Aebi, J. D., Dehmlow, H., Ji, Y. H., Gains, N., Lengsfeld, H., and Himber, J. (1997) Ro 48-8.071, a new 2,3-oxidosqualene:lanosterol cyclase inhibitor lowering 
plasma cholesterol in hamsters, squirrel monkeys, and minipigs: comparison to simvastatin. $J$. Lipid Res. 38, 373-390.

(102) Chan, A. T., Arber, N., Burn, J., Chia, W. K., Elwood, P., Hull, M. A., Logan, R. F., Rothwell, P. M., Schrör, K., and Baron, J. A. (2012) Aspirin in the Chemoprevention of Colorectal Neoplasia: An Overview. Cancer Prev Res 5, 164-178.

(103) U.S. Preventive Services Task Force. (2007) Routine aspirin or nonsteroidal antiinflammatory drugs for the primary prevention of colorectal cancer: U.S. Preventive Services Task Force recommendation statement. Ann. Intern. Med. 146, 361-364.

(104) Giovannucci, E., Egan, K. M., Hunter, D. J., Stampfer, M. J., Colditz, G. A., Willett, W. C., and Speizer, F. E. (1995) Aspirin and the Risk of Colorectal Cancer in Women. New England Journal of Medicine 333, 609-614.

(105) Nan, H., Hutter, C. M., Lin, Y., Jacobs, E. J., Ulrich, C. M., White, E., Baron, J. A., Berndt, S. I., Brenner, H., Butterbach, K., Caan, B. J., Campbell, P. T., Carlson, C. S., Casey, G., Chang-Claude, J., Chanock, S. J., Cotterchio, M., Duggan, D., Figueiredo, J. C., Fuchs, C. S., Giovannucci, E. L., Gong, J., Haile, R. W., Harrison, T. A., Hayes, R. B., Hoffmeister, M., Hopper, J. L., Hudson, T. J., Jenkins, M. A., Jiao, S., Lindor, N. M., Lemire, M., Marchand, L. L., Newcomb, P. A., Ogino, S., Pflugeisen, B. M., Potter, J. D., Qu, C., Rosse, S. A., Rudolph, A., Schoen, R. E., Schumacher, F. R., Seminara, D., Slattery, M. L., Thibodeau, S. N., Thomas, F., Thornquist, M., Warnick, G. S., Zanke, B. W., Gauderman, W. J., Peters, U., Hsu, L., and Chan, A. T. (2015) Association of Aspirin and NSAID Use With Risk of Colorectal Cancer According to Genetic Variants. JAMA 313, 1133-1142.

(106) Yang, G., Wang, Y., Feng, J., Liu, Y., Wang, T., Zhao, M., Ye, L., and Zhang, X. (2017) Aspirin suppresses the abnormal lipid metabolism in liver cancer cells via disrupting an NFkB-ACSL1 signaling. Biochemical and Biophysical Research Communications 486, 827832. 
(107) Li, S., Dai, W., Mo, W., Li, J., Feng, J., Wu, L., Liu, T., Yu, Q., Xu, S., Wang, W., Lu, X., Zhang, Q., Chen, K., Xia, Y., Lu, J., Zhou, Y., Fan, X., Xu, L., and Guo, C. (2017) By inhibiting PFKFB3, aspirin overcomes sorafenib resistance in hepatocellular carcinoma. International Journal of Cancer 141, 2571-2584.

(108) Li, G., Zhang, S., Fang, H., Yan, B., Zhao, Y., Feng, L., Ma, X., and Ye, X. (2013) Aspirin overcomes Navitoclax-resistance in hepatocellular carcinoma cells through suppression of Mcl-1. Biochemical and Biophysical Research Communications 434, 809-814.

(109) Tse, C., Shoemaker, A. R., Adickes, J., Anderson, M. G., Chen, J., Jin, S., Johnson, E. F., Marsh, K. C., Mitten, M. J., Nimmer, P., Roberts, L., Tahir, S. K., Xiao, Y., Yang, X., Zhang, H., Fesik, S., Rosenberg, S. H., and Elmore, S. W. (2008) ABT-263: A Potent and Orally Bioavailable Bcl-2 Family Inhibitor. Cancer Res 68, 3421-3428.

(110) van Delft, M. F., Wei, A. H., Mason, K. D., Vandenberg, C. J., Chen, L., Czabotar, P. E., Willis, S. N., Scott, C. L., Day, C. L., Cory, S., Adams, J. M., Roberts, A. W., and Huang, D. C. S. (2006) The BH3 mimetic ABT-737 targets selective Bcl-2 proteins and efficiently induces apoptosis via Bak/Bax if Mcl-1 is neutralized. Cancer Cell 10, 389-399.

(111) Li, T., Dong, Z.-R., Guo, Z.-Y., Wang, C.-H., Tang, Z.-Y., Qu, S.-F., Chen, Z.-T., Li, X.-W., and Zhi, X.-T. (2013) Aspirin enhances IFN- $\alpha$-induced growth inhibition and apoptosis of hepatocellular carcinoma via JAK1/STAT1 pathway. Cancer Gene Ther 20, 366-374.

(112) Li, J.-H., Xie, X.-Y., Zhang, L., Le, F., Ge, N.-L., Li, L.-X., Gan, Y.-H., Chen, Y., Zhang, J.-B., Xue, T.-C., Chen, R.-X., Xia, J.-L., Zhang, B.-H., Ye, S.-L., Wang, Y.-H., and Ren, Z.-G. (2015) Oxaliplatin and 5-fluorouracil hepatic infusion with lipiodolized chemoembolization in large hepatocellular carcinoma. World Journal of Gastroenterology 21, $3970-3977$. 
(113) Sanoff, H. K., Chang, Y., Stavas, J. M., Stürmer, T., and Lund, J. (2015) Effectiveness of Initial Transarterial Chemoembolization for Hepatocellular Carcinoma Among Medicare Beneficiaries. Journal of the National Comprehensive Cancer Network 13, 1102-1110.

(114) Raoul, J.-L., Gilabert, M., and Piana, G. (2014) How to Define Transarterial Chemoembolization Failure or Refractoriness: A European Perspective. LIC 3, 119-124.

(115) Kudo, M., Matsui, O., Izumi, N., Kadoya, M., Okusaka, T., Miyayama, S., Yamakado, K., Tsuchiya, K., Ueshima, K., Hiraoka, A., Ikeda, M., Ogasawara, S., Yamashita, T., Minami, T., and Japan, on behalf of the L. C. S. G. of. (2014) Transarterial Chemoembolization Failure/Refractoriness: JSH-LCSGJ Criteria 2014 Update. OCL 87, 22-31.

(116) Li, J.-H., Wang, Y., Xie, X.-Y., Yin, X., Zhang, L., Chen, R.-X., and Ren, Z.-G. (2016) Aspirin in combination with TACE in treatment of unresectable HCC: a matched-pairs analysis. Am J Cancer Res 6, 2109-2116.

(117) Icard, P., Wu, Z., Fournel, L., Coquerel, A., Lincet, H., and Alifano, M. (2020) ATP citrate lyase: A central metabolic enzyme in cancer. Cancer Lett. 471, 125-134.

(118) Chajès, V., Cambot, M., Moreau, K., Lenoir, G. M., and Joulin, V. (2006) Acetyl-CoA carboxylase alpha is essential to breast cancer cell survival. Cancer Res. 66, 5287-5294.

(119) Kubatka, P., Kruzliak, P., Rotrekl, V., Jelinkova, S., and Mladosievicova, B. (2014) Statins in oncological research: From experimental studies to clinical practice. Critical Reviews in Oncology/Hematology 92, 296-311.

(120) Holubarsch, C. J. F., Rohrbach, M., Karrasch, M., Boehm, E., Polonski, L., Ponikowski, P., and Rhein, S. (2007) A double-blind randomized multicentre clinical trial to evaluate the efficacy and safety of two doses of etomoxir in comparison with placebo in patients with moderate congestive heart failure: the ERGO (etomoxir for the recovery of glucose oxidation) study. Clin Sci (Lond) 113, 205-212. 
(121) Schlaepfer, I. R., Nambiar, D. K., Ramteke, A., Kumar, R., Dhar, D., Agarwal, C., Bergman, B., Graner, M., Maroni, P., Singh, R. P., Agarwal, R., and Deep, G. (2015) Hypoxia induces triglycerides accumulation in prostate cancer cells and extracellular vesicles supporting growth and invasiveness following reoxygenation. Oncotarget 6, 22836-22856.

(122) Xiang, Y., Stine, Z. E., Xia, J., Lu, Y., O’Connor, R. S., Altman, B. J., Hsieh, A. L., Gouw, A. M., Thomas, A. G., Gao, P., Sun, L., Song, L., Yan, B., Slusher, B. S., Zhuo, J., Ooi, L. L., Lee, C. G. L., Mancuso, A., McCallion, A. S., Le, A., Milone, M. C., Rayport, S., Felsher, D. W., and Dang, C. V. (2015) Targeted inhibition of tumour-specific glutaminase diminishes cell-autonomous tumourigenesis. J Clin Invest 125, 2293-2306.

(123) Gross, M. I., Demo, S. D., Dennison, J. B., Chen, L., Chernov-Rogan, T., Goyal, B., Janes, J. R., Laidig, G. J., Lewis, E. R., Li, J., Mackinnon, A. L., Parlati, F., Rodriguez, M. L. M., Shwonek, P. J., Sjogren, E. B., Stanton, T. F., Wang, T., Yang, J., Zhao, F., and Bennett, M. K. (2014) Antitumour activity of the glutaminase inhibitor CB-839 in triple-negative breast cancer. Mol. Cancer Ther. 13, 890-901.

(124) Rani, R., and Kumar, V. (2016) Recent Update on Human Lactate Dehydrogenase Enzyme 5 (hLDH5) Inhibitors: A Promising Approach for Cancer Chemotherapy. J. Med. Chem. 59, 487-496. 
For Table of Contents Only

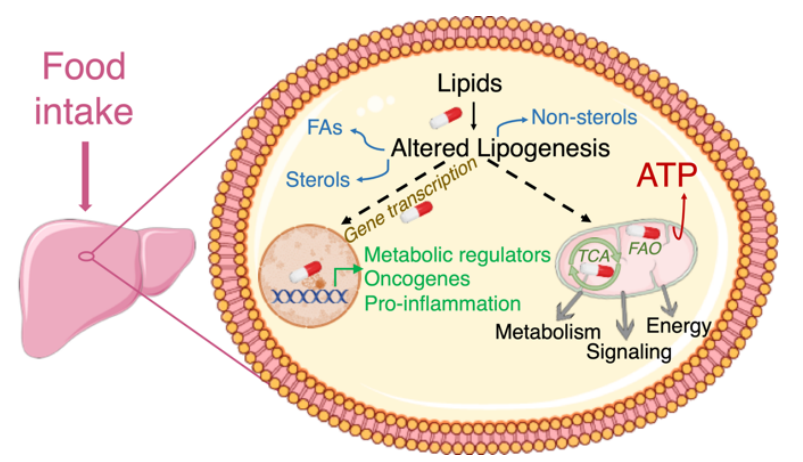

